\title{
Measurement of ambient aerosol hydration state at Great Smoky Mountains National Park in the southeastern United States
}

\author{
N. F. Taylor ${ }^{1}$, D. R. Collins ${ }^{1}$, C. W. Spencer ${ }^{1}$, D. H. Lowenthal ${ }^{2}$, B. Zielinska ${ }^{2}$, V. Samburova ${ }^{2}$, and N. Kumar ${ }^{3}$ \\ ${ }^{1}$ Department of Atmospheric Sciences, Texas A\&M University, College Station, Texas, USA \\ ${ }^{2}$ Division of Atmospheric Sciences, Desert Research Institute, Reno, Nevada, USA \\ ${ }^{3}$ Electric Power Research Institute, Palo Alto, California, USA
}

Received: 13 June 2011 - Published in Atmos. Chem. Phys. Discuss.: 4 August 2011

Revised: 18 November 2011 - Accepted: 22 November 2011 - Published: 7 December 2011

\begin{abstract}
We present results from two field deployments of a unique tandem differential mobility analyzer (TDMA) configuration with two primary capabilities: identifying alternative stable or meta-stable ambient aerosol hydration states associated with hysteresis in aerosol hydration behavior and determining the actual Ambient hydration State (ASTDMA). This data set is the first to fully classify the ambient hydration state of aerosols despite recognition that hydration state significantly impacts the roles of aerosols in climate, visibility and heterogeneous chemistry. The AS-TDMA was installed at a site in eastern Tennessee on the border of Great Smoky Mountains National Park for projects during the summer of 2006 and winter of 2007-2008. During the summer, $12 \%$ of the aerosols sampled in continuous AS-TDMA measurements were found to posses two possible hydration states under ambient conditions. In every case, the more hydrated of the possible states was occupied. The remaining $88 \%$ did not posses multiple possible states. In continuous measurements during the winter, $49 \%$ of the aerosols sampled possessed two possible ambient hydration states; the remainder possessed only one. Of those aerosols with multiple possible ambient hydration states, $65 \%$ occupied the more hydrated state; $35 \%$ occupied the less hydrated state. This seasonal contrast is supported by differences in the fine particulate $\left(\mathrm{PM}_{2.5}\right)$ composition and ambient $\mathrm{RH}$ as measured during the two study periods. In addition to seasonal summaries, this work includes case studies depicting the variation of hydration state with changing atmospheric conditions.
\end{abstract}

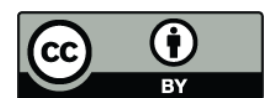

Correspondence to: D. R. Collins (dcollins@tamu.edu)

\section{Introduction}

\subsection{Background}

Atmospheric particulates frequently exhibit transitions between solid and aqueous phases driven by changes in relative humidity. Often, these changes in hydration state are irreversible and display hysteresis due to kinetic limitations on the formation of ordered phases (Tang and Munkelwitz, 1984). For example, ammonium sulfate deliquesces at $\sim 80 \%$ RH but effloresces at $\sim 40 \%$ RH. Between these critical relative humidities, the RH domain of hysteresis, an ammonium sulfate aerosol may occupy one of two hydration states, meta-stable and supersaturated solution or anhydrous crystal, dependent on its RH history. This behavior is illustrated in Fig. 1, which depicts change in particle diameter due to water uptake for an initially crystalline ammonium sulfate aerosol and water loss for an initially aqueous, solution aerosol.

Similar to the idealized ammonium sulfate aerosol, ambient boundary layer aerosol have been observed to display occasional hysteresis at a variety of locations by nephelometry (Brink et al., 1996; Carrico et al., 2000, 2003; Charlson et al., 1974; Day and Malm, 2001; Dougle et al., 1998; Rood et al., 1987; Shaw and Rood, 1990; Swietlicki et al., 2000; Wang et al., 2007) and Tandem Differential Mobility Analyzer (TDMA) measurements (Berg et al., 1998; Gasparini et al., 2006). Hysteresis is not a universal characteristic of ambient aerosol and not consistently detected (FierzSchmidhauser et al., 2010; Pitchford and McMurry, 1994; Rissler et al., 2006; Sjogren et al., 2008; Zhou et al., 2001). This is anticipated by laboratory studies of hysteretic aerosol components. In particular, the hydration behavior of sulfate/nitrate/ammonium/proton (SNA) mixtures has been well established and is marked by decreasing critical relative humidities of deliquescence and efflorescence with increasing acidity (Martin, 2000). When no ammonium is present, these

Published by Copernicus Publications on behalf of the European Geosciences Union. 


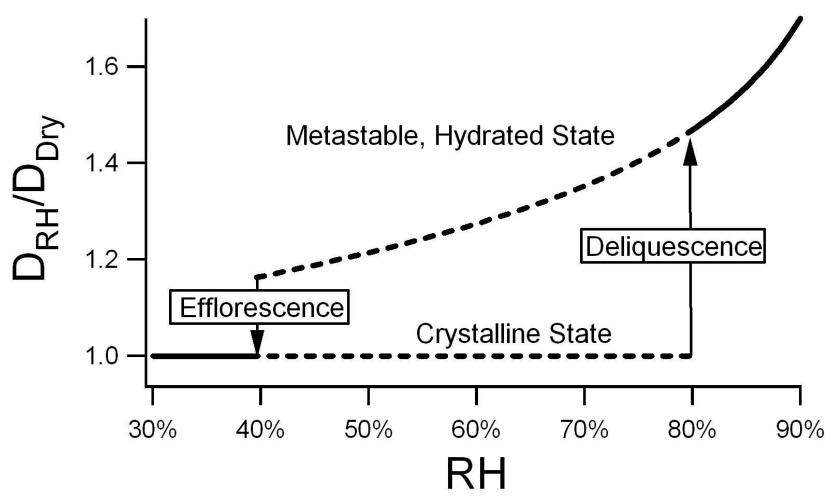

Fig. 1. Idealized ammonium sulfate growth curve.

mixtures display continuous hygroscopic growth and exhibit no phase transitions. Further, in situ measurements of hysteresis often report truncated hysteresis loops and gradual phase transitions with partial hydration of the lower hydration state (Berg et al., 1998). This too is consistent with laboratory studies of various internal mixtures of both inorganic and organic species whose findings indicate complex interactions affecting the $\mathrm{RH}$ and character of phase transitions (Brooks et al., 2002; Ciobanu et al., 2010; Hansson et al., 1998; Martin et al., 2001; Tang et al., 1978).

As aerosol properties may differ greatly between hydration states, knowledge of hydration state of ambient aerosols is critical to understanding their atmospheric roles. In the common case of ammonium sulfate, a meta-stable, aqueous aerosol near the deliquescence RH may feature over 3 times the volume and light scattering per solute mass of the alternative crystalline state. This greatly affects the influence of ammonium sulfate on the global radiation budget as well as local visibility. An expansive treatment of the radiative effects of SNA hysteresis globally was done by Martin et al. (2004) with follow up by Wang et al. (2008a). These studies utilized global 3-D chemical transport models to predict SNA loading, degree of neutralization, extent of hysteresis, and the effect on the global radiation budget of assuming the least hydrated and most hydrated aerosol hydration states. The first of these studies made no attempt to predict the hydration state, but only compared the result of each assumption. They concluded that an assumption of the lower hydration state would produce a $25 \%$ reduction in negative radiative forcing estimate for global SNA versus an assumed aqueous hydration state. The second work, by Wang et al. (2008a), augmented a similar methodology to include model based prediction of hydration state. Unfortunately, it is difficult to gauge the accuracy of this and other modeling approaches (Colberg et al., 2003; Grant et al., 1999; Haywood et al., 1997; Wang et al., 2008b) as limited measurements have been made fully characterizing ambient aerosol hydration state apart from the work of Santarpia et al. (2004) - the precursor to the present endeavor (Swietlicki et al., 2008).
Other current approaches to measuring hydration state are the nephelometry based work of Rood et al. (1987, 1989), the $1 \times 3$ TDMA of Martin et al. (2008) and Rosenoern et al. (2009), and the Dry-Ambient Aerosol Size Spectrometer (DAASS) (Engelhart et al., 2011; Khlystov et al., 2005; Stanier et al., 2004). From the high time resolution of nephelometry to the broad size range examined by the DAASS to the notable sensitivity of the $1 \times 3$ TDMA, each has various advantages. However, when considering the alternative hydration states resulting from hysteresis these approaches have less merit. The work of Rood et al. $(1987,1989)$ only positively indicates the presence of a more hydrated alternative state, while the DAASS does not treat hysteresis. Both could, with sufficient supporting measurements of hysteresis behavior or composition, more fully address alternative hydration states; but this is not inherent in their function. Further, though these instruments do in some fashion retrieve size dependence, it is not with the clarity, resolution, or ability to determine mixing characteristics available to TDMA based systems. Alternatively, the $1 \times 3$ TDMA has advantages of sensitivity as well as the capability to indicate hysteresis and the ambient hydration state. But this capability has yet to be exploited in field deployments.

The present work develops the methodology of Santarpia et al. (2004), which augmented and modified the conditioning process used by Rood et al. $(1987,1989)$ to positively determine the existence of both aerosol in a more hydrated, meta-stable state and aerosol in a less hydrated state. This system, termed an Ambient State (AS)-TDMA, takes full advantage of the high resolution and size resolving operation available to TDMA based instruments. A description of the operation and configuration of the AS-TDMA occupies first portion of this manuscript. Further details on the analysis of its unique results are given as an appendix. The second and greater part of this manuscript reports the findings from two field deployments of the AS-TDMA.

\subsection{Study details}

This paper reports results from a succession of two measurement campaigns conducted on the boundary of Great Smoky Mountains National Park in Tennessee. To retrieve seasonal variation, the first took place during the summer of 2006 (20 July-30 August) and the second in the winter of 2007-2008 (1 November-10 February). The measurements were made at the Look Rock site, which is located on a ridge overlooking the northwest boundary of the park. This site is approximately 30 miles south of Knoxville, TN. In addition to the measurements described here, the site houses both an Interagency Monitoring of PROtected Visual Environment (IMPROVE) station and an air quality station operated by the Tennessee Valley Authority. It has been the location of several intensive studies including the Southeastern Aerosol Visibility Study (Day et al., 2001). The site is typical of the southeastern region of the US, known to posses high loading 
of sulfate aerosol resulting in significant degradation of visibility. Measurements were conducted from the roof of a temporary building, positioned near both the IMPROVE and TVA facilities, that housed the bulk of the instrumentation.

These studies were conducted as part of a larger campaign aimed at evaluating several facets of the IMPROVE program (Lowenthal et al., 2009). That project centers on four areas related to conventions used within the IMPROVE program to relate filter-based composition measurements to light extinction: organic aerosol hygroscopicity; the ratio of organic aerosol mass to organic carbon mass; the attribution of fine aerosol mass into size distributions as necessary to predict optical effects; and aerosol ambient hydration state, necessary to estimate the visibility impacts of sulfate and nitrate mass (Pitchford et al., 2007). The AS-TDMA was deployed to investigate the last of these. Aside from this issue, however, the results presented here have broader implications for the understanding of the atmospheric roles of aerosol.

While the primary instrument described in this report is the AS-TDMA, two other sources of information are used to support the findings. The first is compositional analysis of daily, high-volume and medium-volume $\mathrm{PM}_{2.5}$ (particles with diameters smaller than $2.5 \mu \mathrm{m}$ ) filter samples (Lowenthal et al., 2009). The other source is an ancillary H-TDMA (hygroscopic-TDMA) system operated to complement the AS-TDMA.

\section{Methodology}

The measurement of ambient hydration state was achieved with a three part experimental process utilizing a modified TDMA. The technique is elaborated here as follows: first, the AS-TDMA instrument is described, especially as it deviates from the conventional TDMA configuration. Next is illustrated how the configuration translates in operation to the experimental procedure for the determination of hydration state. Meta-experimental parameters such as measurement frequency are discussed following the operation illustration. Finally, the procedures used to refine the AS-TDMA results are introduced, though their detailed discussion is deferred to Appendix A.

\subsection{AS-TDMA instrumentation}

The AS-TDMA shares operational principles of TDMA systems: determining the effects on particle size of some process such as heating or humidifying. To measure hydration state, the AS-TDMA retrieves the different effects on the size of an ambient aerosol of three distinct processes: a Deliquescence Forcing (DF), an Efflorescence Forcing (EF) and a Drying process. The modifications necessary to execute these processes on an ambient aerosol are significant but do not involve alterations of the essential TDMA elements. A very brief review of several salient features of TDMAs is included in this section. Further, while the components and configuration involved in the modification are described, no corresponding description is given for the non-unique portions of the AS-TDMA instrument. For details both on TDMA concepts and the specific components, operation, performance and control of the TDMA system modified to form the ASTDMA, the reader is referred to Gasparini et al. (2004).

All TDMA systems rely on two electrostatic classifiers, often called DMAs, which each acts as a controllable "bandpass" filter on particle electrical mobility. While mobility is determined by both size and morphology, it is convenient to refer to mobility in terms of that of a sphere. Thus, in this paper all mention of size with respect to TDMAs refers to the size of a sphere of equivalent mobility. TDMA utilize the two classifiers in series. The first classifier is controlled to transmit an ensemble of particles with fixed, constant diameter from the aerosol being sampled. The resultant, roughly monodisperse aerosol is then subject to a process (e.g. humidification, heating) that could modify the size of the particles. This creates a particle ensemble in which size reflects responsiveness to the inter-classifier process (e.g. hygroscopicity, volatility). This final size distribution is captured by the second classifier, operating in a scanning configuration, in conjunction with a condensation particle counter (CPC). The count rates recorded by the CPC are inverted to retrieve the size distribution.

There are two primary features of the AS-TDMA modification: the first electrostatic classifier is operated to preserve ambient RH and temperature and a series of three measurements with different inter-classifier RH conditioning processes are employed. This section describes the implementation of these features and their utility in retrieving ambient hydration state. A schematic of the implementation is provided at the top of Fig. 2.

As illustrated in the schematic, the first classifier is located in the ambient environment. In addition, care is taken to ensure that it operates at ambient $\mathrm{RH}$ and temperature to remove perturbations in ambient conditions before the aerosol has been transmitted through the classifier column. The object being to select a monodisperse aerosol based on ambient size and especially ambient hydration state. This is a significant difference from common TDMA and is necessary to obtain information about the ambient condition of the aerosol. For this study, the external unit was located on the roof of the climate controlled trailer housing the remaining instrumentation. The unit is shrouded with a heavy, white cover to guard against weather and direct solar heating. In addition, a high volume fan circulates ambient air rapidly around the instrument components to enhance temperature equilibration. The ambient aerosol is sampled with a simple inlet and passes through a Po-210 based neutralizer before entering the first classifier. Immediately downstream of the classifier, a Vaisala HMM-22D RH probe, also maintained at ambient conditions, captures the RH of the aerosol sample flow. This, the "Ambient RH" probe, and other Vaisala RH probes 


\section{AS-TDMA}

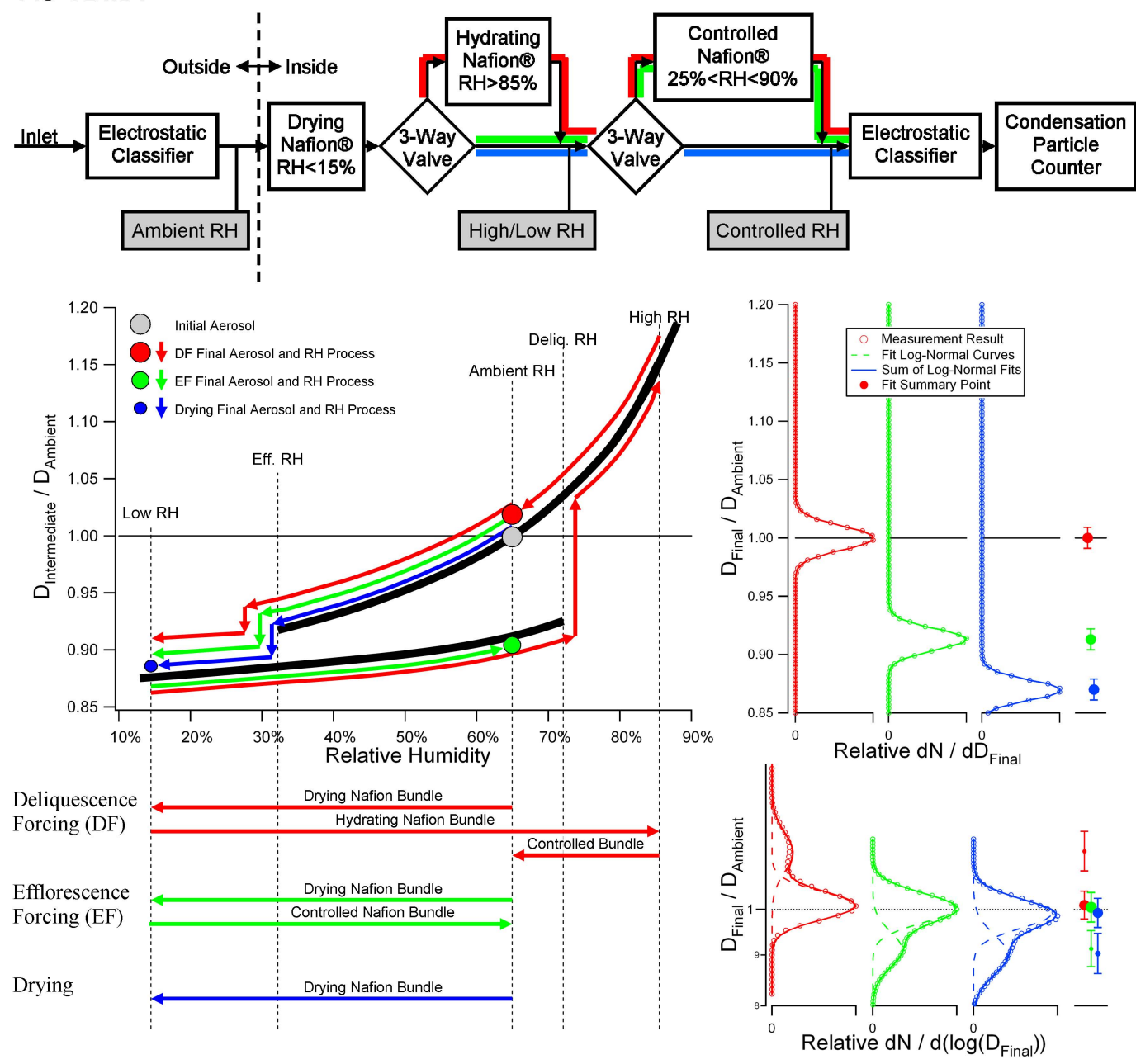

Fig. 2. AS-TDMA schematic and experimental procedure illustration. The configuration and results for the DF, EF and Drying process are shown in red, green and blue, respectively. The grey elements of the schematic represent RH Probes. The procedure illustration depicts AS-TDMA operation on a hypothetical aerosol found in a more hydrated state at $65 \% \mathrm{RH}$. Its hydration characteristics are illustrated in the upper-left chart. The arrows in the upper left and lower left depict the manipulations of RH achieved in the Nafion tube bundles. The resultant size distributions produced by the process measurements are shown in upper-right corner. In the lower-right, an example taken from the winter study period is displayed. Shown along the right edge is a compact convention for displaying the results.

are shown in grey in the schematic. At this point the aerosol is directed inside and into a temperature controlled enclosure $\left(29^{\circ} \mathrm{C}\right)$ in order to facilitate the stable manipulations of $\mathrm{RH}$ that constitute the inter-classifier processes. This admits the possibility of some volatilization of compounds such as ammonium nitrate; yet, hopefully with limited impact on the results (cf. Sect. 3.1.1 for the impact of ammonium nitrate volatilization on hydration behavior and Appendix A4 for the recovery of systematic mass loss).

The middle portion of the schematic describes the three alternate configurations that achieve the three inter-classifier processes used to resolve ambient hydration states. The individual processes will be referred to as the Deliquescence Forcing (DF) process, the Efflorescence Forcing (EF) pro- cess and the Drying process. They are depicted in red, green and blue, respectively, in the schematic and in the balance of the paper.

Each of the processes consists of a different sequence of RH manipulation conducted using variously configured Perma Pure Nafion PD-07018T moisture exchange tube bundles. The first, moving from left to right in the schematic, is configured to dry the aerosol with its purge flow held at high vacuum. The "High/Low RH" probe measures the extent of drying by this Nafion bundle during the EF and Drying processes. Drying varied narrowly during this study and the RH of the aerosol sample flow exiting this exchange was consistently between 8 and $15 \%$ RH. The second moisture exchange is configured to hydrate the aerosol sample 
flow by maintaining very high $\mathrm{RH}(>95 \%)$ in the purge flow. It achieved consistent sample flow humidification to $>85 \% \mathrm{RH}$, measured by the "High/Low RH" probe during DF measurements. The final Nafion bundle is configured to be controllable. The purge flow contains a high mixing ratio of water, but the purge pressure (vacuum) is controllable. This allows the vapor pressure differential to vary and with it the moisture flux between the purge and sample flow. The "Controlled RH" probe measures the RH of the sample flow exiting this exchange. The RH produced by this Nafion bundle is controlled to mirror the ambient RH measured by the "Ambient RH" probe using a tuned PID (proportional/integral/derivative) routine. Typical displays of its performance are included in Figs. 8 and 9 in the results section, where the average retrieved Ambient $\mathrm{RH}$ and Controlled $\mathrm{RH}$ values for a series of measurements are shown. The averages depicted are for $180 \mathrm{~s}$ intervals corresponding to the duration of a single measurement.

The three different inter-classifier processes are produced by a series of 3-way valves that determine which Nafion bundles the sample flow is directed through. Each of the processes begins with the initial drying Nafion bundle. This drying bundle is placed immediately within the housing trailer. Apart from its role in the processes, it serves to prevent condensation in the tubing segment exposed to the low (air-conditioned) temperature in the trailer that conducts the aerosol into the internal and finely-temperature-controlled instrument enclosure. From this point, the RH manipulations of the processes diverge. The path followed during the DF process is shown in red. It conditions the aerosol to a high $\mathrm{RH}$ and then restores the $\mathrm{RH}$ to the ambient level. This process is intended to resolve the presence of ambient particles exhibiting hysteresis and occupying a less hydrated state. The EF process, shown in green, only returns the dried sample flow to its ambient RH. The EF process resolves the presence of particles in a more hydrated state. The Drying process, shown in blue, leaves the aerosol sample flow at low RH. This produces a final aerosol stream in which particle size reduction from the size selected by the first classifier reflects the amount of water initially present in the particles.

The remainder of the AS-TDMA is configured in the standard fashion to retrieve the resultant size distributions of each process. Beyond the two primary modifications here discussed, the AS-TDMA differs from the Gasparini et al. (2004) TDMA cited above in only two other significant aspects. In conventional H-TDMAs, to maximize separation of size distribution modes comprised of populations of particles having similar hygroscopicities, the inter-classifier $\mathrm{RH}$ is typically maintained at around $90 \%$. In contrast, the effective $\mathrm{RH}$ in the AS-TDMA is not prescribed and ranged from 40 to $90 \%$ for the measurements reported here. To partially compensate for the resulting compression of size modes, a higher than usual 13:1 sheath to aerosol flow ratio was employed in the DMAs. Further, the CPC in the AS-TDMA was a TSI model 3762 capable of handling higher sample flow rates and producing better counting statistics than that used by Gasparini, et al. (2004) As a final note on configuration, higher count rates achieved through the use of high flow DMAs (HF-DMAs; Stolzenburg et al., 1998) in both the AS- and Gasparini TDMA also aided production of narrow modes that were more easily identified and isolated.

\subsection{AS-TDMA experimental process and operation}

The following illustration describes the operation of the ASTDMA on a hypothetical aerosol with given hydration characteristics; explicitly covering the effects on the aerosol sample flow as it is transmitted through the three processes as well as the form and type of result each process generates. In addition, consideration is given to what response departures from the hypothetical aerosol would produce in the results to fully establish how AS-TDMA experimental processes resolve hydration state. This subsection concludes with metaexperimental parameters such as measurement frequency and size.

The following descriptions refer especially to the portion of Fig. 2 below the instrument schematic, which variously depicts the application of the three processes to an ideal, internally mixed aerosol. The particles in this ensemble have the hydration characteristics illustrated in the upper left: an efflorescence RH of $34 \%$ and a deliquescence RH of $72 \%$. The abscissa describes the ratio of the diameter of the particles to the initial, ambient diameter selected by the first classifier. The aerosol is depicted as initially in its most hydrated state at an ambient RH of $65 \%$. This is illustrated by the large grey dot at the intersection of the ambient RH and unity size ratio lines. The arrows below this chart describe the $\mathrm{RH}$ to which the aerosol particles are exposed during each of the three processes. The corresponding response in the size of the aerosol particles is traced along the hydration profile above. In the upper right, the resultant normalized size distribution produced by each process is shown, reflecting the distributed response of the instrument to an ensemble of uniform, internally mixed particles. A set of measurements made during this study is shown in the lower right to illustrate several analysis steps. Shown along the right margin are symbols illustrating a compact method of describing the size distributions.

Each of the three processes begins with an approximately monodisperse aerosol stream supplied by the first classifier. This stream is directed into the indoor portion of the instrument and passed through the drying Nafion bundle, as indicated in the instrument schematic. As the monodisperse aerosol passes through this Nafion, the RH of the carrier gas decreases to a low RH $(\sim 15 \%)$ and most of the particulate water evaporates. This is depicted in the upper left hand portion of the illustration by the three parallel sets of arrows that trace the growth curve away from the initial ambient size and $\mathrm{RH}$, the point marked by a grey dot, downward and to the left. In the lower left portion of the illustration, the first 
arrow in each color depicts the change in $\mathrm{RH}$ and is labeled "Drying Nafion Bundle" to relate what element in the instrumentation effects the change. For the hypothetical aerosol, this transition includes the efflorescence of the aerosol. As the hypothetical aerosol is dried to levels below its efflorescence point, the illustration depicts it losing additional water. The aerosol size at this point reflects how much water it initially contained. If the aerosol had initially been in its least hydrated state, the reduction in size would have been less dramatic. If the initial monodisperse aerosol had contained an external mixture of particles containing different amounts of water, it would become polydisperse with drying. At this point, the three processes diverge and the now dry aerosol stream is diverted according to each program of RH manipulation producing the following results:

- Deliquescence Forcing (DF): this process follows the path in the schematic and the illustrated features shown in red. It resolves the presence of ambient, hysteretic aerosol in less hydrated states. During this process, the aerosol stream is diverted by the first 3-way valve into the hydrating Nafion bundle. This increases the RH of the aerosol to at least $85 \%$. The effect on the illustrated aerosol is traced by the red arrows away from the low RH and small particle size, along the least hydrated branch of the growth curve until the aerosol particles deliquesce at $72 \% \mathrm{RH}$. At RH levels above the deliquescence point, only one hydration state exists and the aerosol particles continue to take up water until high RH $(>85 \%)$ is achieved. Because this RH is above the deliquescence point, the effects of the initial drying and efflorescence are removed. Next, the aerosol enters the controlled Nafion tube bundle, which is configured to restore ambient RH levels. Thus, the final red arrow in the process depicts the aerosol being restored to ambient RH. This causes the aerosol particles to lose water as they are exposed to decreasing RH. As is depicted in the upper right, the aerosol is restored to its initial condition and its particles to their initial size. The resultant size distribution recorded is shown to the right. It is centered at a unity ratio of final to initial size. The breadth of the distribution reflects the actual range of sizes in the approximately monodisperse aerosol transmitted by the first classifier. If the particles had instead been initially in their least hydrated state, the RH manipulations in this process would have forced them to deliquesce, leaving the particles larger and in their most hydrated state. If the aerosol did not exhibit hysteresis this process would not alter it. Finally, if the aerosol was externally mixed, the resultant size distributions from this and the other processes would contain, superimposed, the responses of the different factions in the aerosol. For example, the results in the lower left depict an external mixture with several distinct populations.
- Efflorescence Forcing (EF): this process follows the green path through the instrument and resolves the presence of hysteretic ambient aerosol in a more hydrated state. During this process, the aerosol bypasses the hydrating Nafion bundle. The controlled Nafion is again operated to mirror the ambient RH. As traced on the growth curve, the result of this process is to move the aerosol from its most hydrated state to its less hydrated state, forcing its efflorescence. If the aerosol had been initially in the less hydrated state, or if it did not exhibit hysteretic phase transitions, there would be no change in the size of its particles. For the case illustrated, the reduction in size is shown in the resultant size distribution on the right.

- Drying: in this final process the blue path is followed and both the hydrating and controlled Nafion are bypassed. This preserves the dry state of the aerosol. The growth curve depicts a reduction in size greater for this process than that caused by the EF process. This results in the size distribution being centered about a lower ratio of final to initial diameter than for the EF process. If the aerosol had been initially in its least hydrated state then the decrease in size would be reduced. If the aerosol did not display hysteretic phase changes, the aerosol would still display water loss, dependent on the aerosol hygroscopicity.

From this illustration, the purpose and use of each process should be mostly apparent: the growth of aerosol particles caused by the DF process implies that the aerosol is hysteretic and in a less hydrated state initially. Similarly, a reduction in aerosol particle size caused by the EF process indicates that the aerosol is hysteretic and in a more hydrated state initially. The Drying process resolves the ambient water content of aerosols, the use of which is elaborated in the next subsection. The comparative more- or less-hydrated state will be used henceforth to reference hysteretic aerosol hydration states detected by the EF and DF processes, respectively. This convention is used in deference to the plausibility of intermediate hydration states and multiple crystalline forms (Mifflin et al., 2009; Rosenoern et al., 2008). Further, this reserves the possibility of water content in less hydrated states.

During this study each of the three process measurements was conducted for five ambient sizes: $0.025,0.05,0.1,0.2$, and $0.4 \mu \mathrm{m}$. In operation, a measurement for every size was conducted using each process before transition to the next. The DF process was conducted first, the EF second and the Drying process last. The time resolution of these measurements varied based on the length of each individual measurement, which was varied between 3 and $5 \mathrm{~min}$, as CPC count rates allowed. An additional $100 \mathrm{~s}$ was required between each size measured for the change in size selected by the first classifier to penetrate and achieve steady state in the remainder of the instrument. The transitions between the 
processes required a period of equilibration as the controlled Nafion bundle adjusted to changes in the RH of the sample flow and for changes in RH to permeate the second classifier. It was determined that $300 \mathrm{~s}$ was sufficient for the transitions from DF to EF and from EF to Drying processes. For the transition from Drying to DF process, to begin the next measurement sequence, $900 \mathrm{~s}$ was required. In sum, each full measurement cycle took 120-150 min.

Measurements were continuously conducted at this frequency except when instrument limitations forced temporary suspension of operation. These limitations were threefold. First, to avoid condensation within the external classifier column, measurements were suspended when ambient RH was higher than $90 \%$. Second, the controlled Nafion bundle produced a minimum RH of approximately $25-30 \%$. Therefore measurements were also suspended below that threshold. Finally, to avoid frost build up, measurements were suspended, the circulation fan in the external unit was switched off and a small heater was powered on when ambient temperature fell below $0^{\circ} \mathrm{C}$. The effect of these limitations on measurement coverage is illustrated in Fig. 3 and discussed in the final paragraph of Sect. 3.3.3. The most common cause for measurement suspension was high RH and a corresponding depression in measurement frequency at night is evident in the charts for both studies.

\subsection{AS-TDMA data treatment}

AS-TDMA results take the form of size distributions, as illustrated on the right side of Fig. 2. While this form is adequate for simple evaluations, additional procedures were applied to refine the results and to facilitate more complicated analysis. These are detailed in the elements of Appendix A titled Log-Normal Curve Fits, Mode Correlation, Hygroscopic Growth Model Use, and Qualification of Hysteresis and Scan Offset. Two final elements cover the treatment of multiply charged particles and AS-TDMA calibration. The following distillation introduces the essential concepts from these processes.

All subsequent presentations of AS-TDMA findings rely on the characterization of the resultant size distributions as a sum of weighted log-normal probability distributions. This is intended to isolate and succinctly describe distinct fractions or modes in the distribution. These log-normal characterizations are depicted in this work as shown at the far right in Fig. 2: each mode isolated by a log-normal distribution is depicted as a single symbol. The size of the circular portion reflects the fraction (by number concentration) of the total size distribution accounted for by the individual log-normal curve. The vertical position of the symbol indicates geometric mean diameter (or size ratio). Lastly, the length of the error bars indicates the breadth of the mode and is one geometric standard deviation. In the lower right, an application of this technique to a set of results from this study is illustrated.
The remaining major elements of Appendix A describe the procedures used to refine the AS-TDMA findings. Mode Correlation describes the essential process of relating the results from the three different inter-DMA processes. Hygroscopic Growth Model Use covers methods of retrieving errors introduced by occasionally fraught RH control. Also, a use for normalizing results under $\mathrm{RH}$ (similar to $\mathrm{GF}_{90 \%}$ ) is described. Finally, Qualification of Hysteresis and Scan Offset establishes flexible methods for determining whether a set of measurements indicates the presence of hysteresis. This qualification is then justified as a means for correcting otherwise irretrievable measurement errors.

\section{Results and discussion}

This section is broken into three parts. The first contains ancillary descriptions of the study periods including relative humidity and temperature, fine particulate $\left(\mathrm{PM}_{2.5}\right)$ composition from diel filter based measurements, and H-TDMA results. The two remaining parts present the AS-TDMA results; first as case studies and individual measurements and subsequently as various study length summaries.

\subsection{Seasonal characterizations and ancillary results}

The strongest feature in the AS-TDMA results is the contrast between the two study periods. During the summer campaign (20 July-30 August 2006) $12 \%$ of AS-TDMA measurements indicated ambient aerosol in a more hydrated state, while no measurements indicated ambient aerosol in a less hydrated state and the balance of measurements showed no hysteresis. The winter campaign (1 November 200710 February 2008) measurements indicated $32 \%$ and $17 \%$ of sampled particles to be in more and less hydrated states, respectively. Moreover, the seasonal contrast is well supported by the differences between the $\mathrm{PM}_{2.5}$ composition and ambient RH measured during the two study periods. Thus, the comparison of the seasonal results is a consistent element in the presentation of these findings. In this subsection, the salient contrasts in the seasonal conditions evident in the ancillary material are highlighted. This is followed by a brief summary of H-TDMA measurements as they support ASTDMA findings.

\subsubsection{Seasonal characterizations}

The diurnal variation of $\mathrm{RH}$ and temperature during each study period is shown in Fig. 3. RH is a primary factor in both the appearance of hysteresis and in determining hydration state. Temperature does modulate the RH for phase transitions but is a factor secondary to composition. Additionally, though not treated in this paper, the temperature depictions suggest heating rates and boundary layer dynamics that influence RH history of surface aerosol. The summer period was characterized by a consistent diurnal pattern of warming 

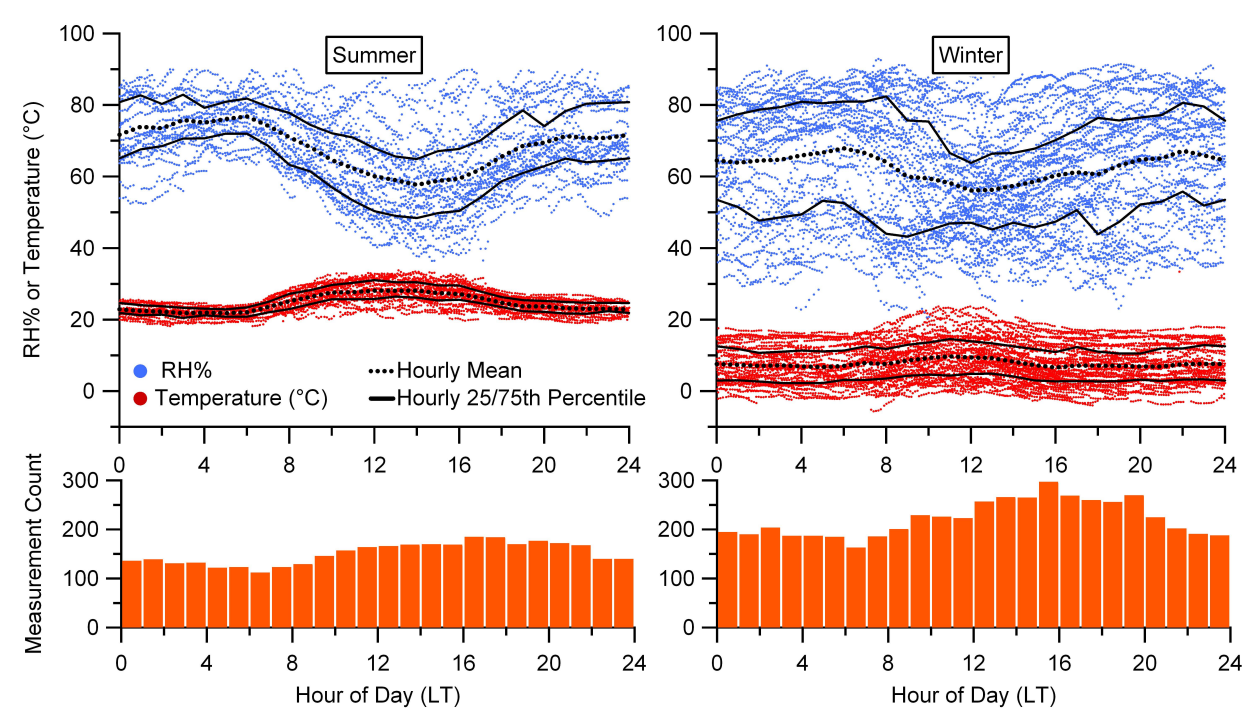

Fig. 3. Diurnal temperature, RH and measurement frequency. Each colored point in the RH and temperature plots is the average value during a single EF, DF or Drying process measurement. A point exists for every measurement during each study. The cessation of operation beyond certain RH and temperature limits discussed at the end of Sect. 2.2 produces corresponding artifacts, e.g. few RH points above $90 \%$. The bottom charts show the diurnal measurement frequency, counting each size distribution recorded.

and drying through the morning and cooling and humidifying through the evenings. Very low levels of RH were infrequently reached, which contributed to the dearth of observed less hydrated ambient states. The winter RH values varied widely. The RH did reach lower levels than during the summer, partially explaining the increased observance of aerosol in less hydrated states. The lack of a consistent diurnal cycle during the winter is also evident in Fig. 3.

Along with RH history, the critical RH levels for irreversible phase transitions determine hydration state. These levels are primarily driven by particulate composition with secondary influences from morphology and temperature. During month-long intensive portions of each study period, daily filter based $\mathrm{PM}_{2.5}$ composition measurements were made (Lowenthal et al., 2009). As with seasonal variation in meteorological conditions, the composition of fine aerosol was quite different between the two studies. The results are shown in Fig. 4 together with the expected annual variation derived from measurements made at the on-site IMPROVE network facility and the expected RH levels for complete deliquescence of a solid composed of sulfate, nitrate and ammonium in the proportions determined by the measurements.

The estimation of the RH levels necessary for full dissolution was made using the Aerosol Inorganics Model (AIM) (Clegg et al., 1998a, b; Clegg and Brimblecombe, 2005). These estimations are intended to aid in interpreting the seasonal composition variation. The calculations neglect surface tension and assumed a temperature of $298.15 \mathrm{~K}$. Also, only the sulfate, nitrate and ammonium fractions were considered. While the neglect of the measured organic components was primarily motivated by a practical lack of ther- modynamic data, the effect of heterogeneities in the quantities measured on deliquescence RH is generally a reduction of less than $10 \%$ RH (Brooks et al., 2002; Choi and Chan, 2002), often much less (Cruz and Pandis, 2000; Hansson et al., 1998; Smith et al., 2011). Exceptions can be found in the work of Marcolli et al. (2004), though these occur with organic aerosol fractions significantly larger than indicated by the filter measurements in consideration. Consequently, these dissolution values are reasonable first order approximations. Beyond these limitations, filter measurements produce results integrated over the sub- $2.5 \mu \mathrm{m}$ size range and $24 \mathrm{~h}$ time periods. Their relationship to highly size and time resolved AS-TDMA results is accordingly loose.

Filter based measurements are also fraught with volatilization issues, especially of ammonium. However, the sensitivity of dissolution behavior predicted by AIM to the volatilization of ammonium is quite moderate. This claim is based on the supposition that the ammonium lost is associated with nitrate and that the locally ubiquitous sulfate fraction of any aerosol particle containing ammonium nitrate is fully neutralized (Seinfeld and Pandis, 2006). Thus, it is expected that the winter dissolution estimations were only moderately, artificially high.

Bearing these reservations in mind, broad seasonal differences are persistent. The summer, characterized by high sulfate loading and insufficient ammonium for neutralization, has lower expected full dissolution RH levels. The winter samples were generally neutralized with accordingly high dissolution RH estimations. This difference follows the seasonal trend illustrated in the earlier IMPROVE dataset. The IMPROVE results shown were taken during the period from 


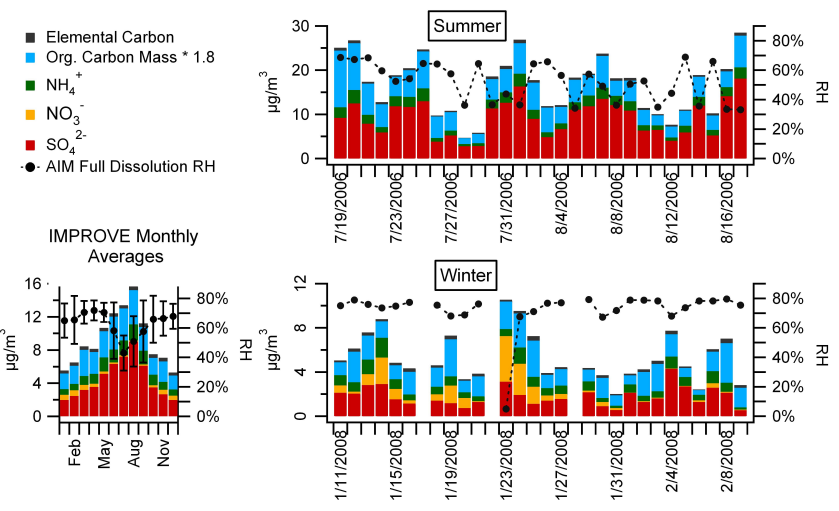

Fig. 4. Daily $\mathrm{PM}_{2.5}$ Filter based measurements made on site at Look Rock near Great Smoky Mountains National Park from Lowenthal et al. (2009) and the IMPROVE network. IMPROVE values are computed as the average of all days within each month during the period from 1997-2006 in which $\mathrm{NH}_{4}^{+}$ions were measured. The black traces showing expected full dissolution RH were calculated for the measured sulfate/nitrate/ammonium proportions using the Aerosol Inorganics Model (AIM).

1997 to 2006 in which ammonium was included in the filter analysis. These results show a yearly cycle in which peaks in sulfate and nitrate correspond to depressions in expected dissolution thresholds. It is this seasonal variation in the location of the full dissolution $\mathrm{RH}$ along with the seasonal change in ambient RH conditions that likely produced the more frequent detection of hysteretic aerosol during the winter measurement periods than the summer. The correlation between filter results and hysteresis detection is explored more fully in the final AS-TDMA results subsection (Sect. 3.3.4).

\subsubsection{TDMA results}

An H-TDMA was operated during both campaigns. During the summer campaign, measurements were intermittent due to instrumentation issues. The winter operation was less fraught and more generally useful. In Fig. 5, an H-TDMA $\mathrm{RH}$ scan from each project is shown along with a summary of the phase transition findings from the winter campaign. The two example scans are sufficiently typical and highlight the amount of water operative in AS-TDMA measurements. Fifty-six full RH scans for each size $(0.05$ and $0.2 \mu \mathrm{m})$ were conducted during the winter. The frequency plot indicates the fraction of these with the given phase transition $\mathrm{RH}$. While knowledge of phase transition RH is an essential element in relating atmospheric conditions to local hydration state, in the present work these results primarily serve to indicate common RH levels for phase transition during the study and thus reinforce AS-TDMA results. The discrepancy between the observed deliquescence point and that predicted from composition (Fig. 4) is reasonable given loose correlation between filter and TDMA based measurements. Finally, the H-TDMA phase transitions compare well with the average winter deliquescence $\mathrm{RH}$ roughly indicated by the AS-TDMA results as shown in Fig. 12 and discussed in Sect. 3.3.3.

\subsection{Individual measurements: full cycle sets and time series}

This first section of AS-TDMA findings contains depictions of individual measurements in two arrangements: single full measurement cycles of all sizes and processes, and in sequence as time series. These serve as case studies, depicting typical phenomena from the two studies. The measurement cycle depictions primarily feature size-dependent hydration characteristics while the time series illustrate transitions in hydration behavior driven by changing ambient RH.

\subsubsection{Individual measurement sets}

The results of three full measurement cycles from both the summer and winter study periods are shown in Figs. 6 and 7. Each full cycle contains 15 measurements: one for each of the five sizes measured during each process. The plots utilize the scheme for depicting these distributions introduced in the methodologies (Sect. 2.3) and illustrated to the far right in Fig. 2. Here, five such depictions, corresponding to the five ambient sizes considered, are arrayed side-by-side: the ambient diameter is the abscissa.

Figure 6 shows three measurement cycles from the summer study period. The first of these depicts no hysteresis, evidenced by the near unity size ratio of the results from the DF and EF process measurements. The slight departures from unity are typical of the noise level in most of the measurements. The remaining two plots depict hysteresis for some of the ambient sizes, shown by less than unity size ratios (i.e. water loss) in the EF results. In these two plots, the portion of particulate water involved in hysteresis varies with size, with an apparent maximum inside the set of sizes measured. It is also interesting that not all of the water in the particles is lost in the EF process, illustrated by the greater water loss in the Drying measurements than in the EF measurements. This is a typical summer feature and is revisited in the study summaries of the next subsection.

Summer results were highly regular and these three results typify that study well. As noted above, no summer measurements detected less hydrated, hysteretic aerosol. Approximately $31 \%$ of the 318 full measurement cycles recorded during the summer included a more hydrated, hysteretic fraction at some size. Of these, $81 \%$ displayed a variation of hysteretic water with particle size similar to that shown in the second and third plots, though the location of the apparent maximum varied. In addition, $90 \%$ of the cycles showed increasing hygroscopicity with size.

The persistent variation of hysteretic water with size is worth consideration. Due to limited supporting data, no conclusions can be drawn; however, the following plausible 

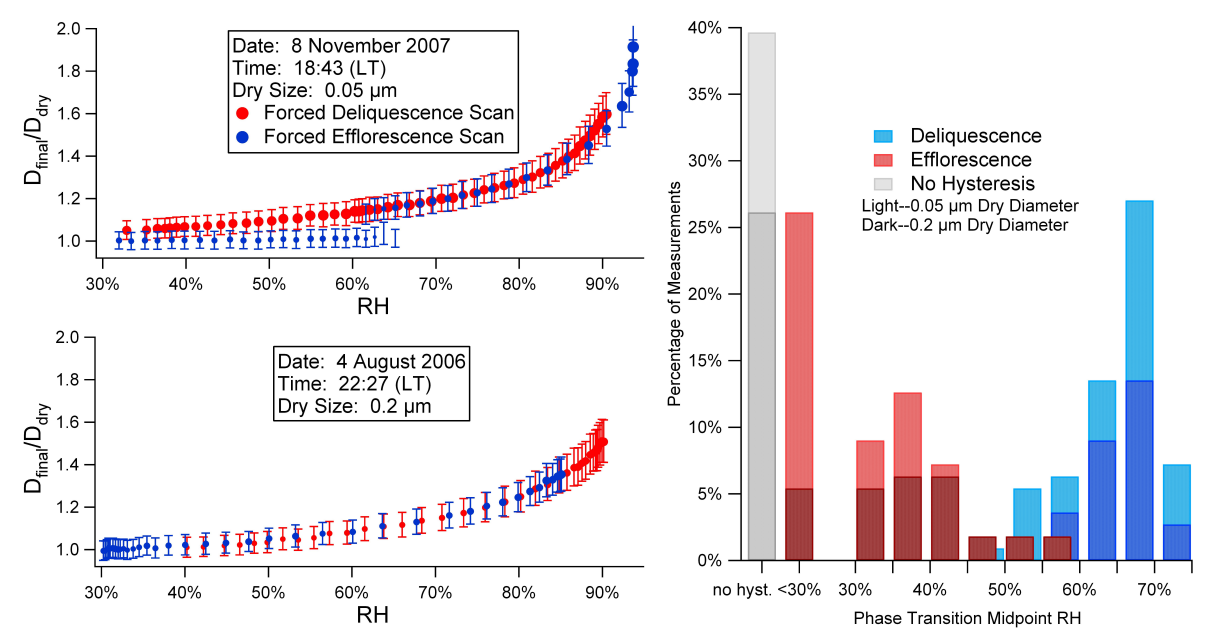

Fig. 5. H-TDMA example scans and winter H-TDMA detected phase transition summary. The points in the H-TDMA scans follow the convention established at the end of Sect. 2.3.

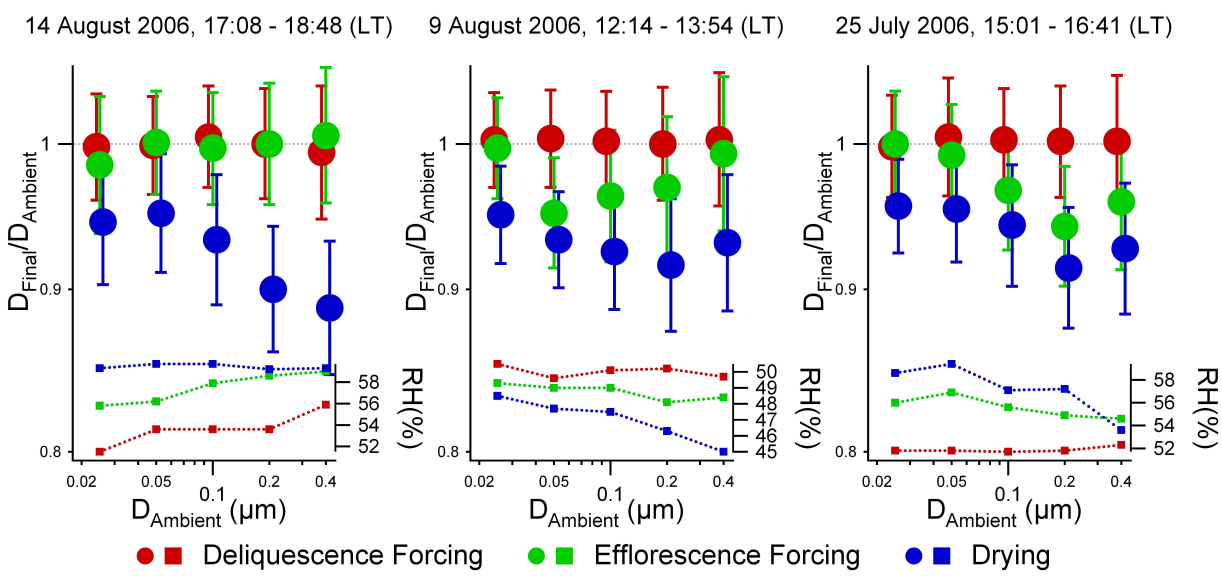

Fig. 6. The results of three AS-TDMA full measurement cycles from the summer campaign. The point and error bar markers follow the convention described in Sect. 2.3: each point characterizes a mode in the size distribution. The size of the point reflects the relative contribution of the mode to the concentration of particles having that ambient diameter; the vertical position depicts the characteristic ratio of post-process to ambient size of particles in the mode; and the error bars describe the breadth of the mode. Below the measurement results is the ambient RH during each measurement. The slight lateral offset between the results from each process is artificial and for clarity only.

hypotheses have been suggested: a reduction in hysteretic water occurs selectively for larger sizes activated as cloud condensation nuclei, driven by the rapid addition of sulfate in cloud processing. This increases the acidity of particles, reduces the deliquescence $\mathrm{RH}$, and increases the likelihood of partial and stepwise dissolution of solids. The lack of hysteresis in the small sizes is caused by mechanisms driving the growth of nucleation mode aerosol such as the addition of secondary organic mass. This is supported by the generally lower hygroscopicity indicated by the Drying process for smaller sizes.

The winter results showed greater variety and the three plots in Fig. 7 from that study do not typify the period. The $0.1,0.2$ and $0.4 \mu \mathrm{m}$ ambient size results in the first plot de- pict two populations, one hysteretic and more hydrated and one containing little or no water. With the smaller sizes, it is possible that the single EF and Drying process modes contain two convoluted modes - illustrating the resolution limits of the AS-TDMA and challenges in fitting data. It is notable that the EF and Drying process results for the larger sizes are almost identical, which implies that there is little residual water in the less hydrated form of the hysteretic population. The second plot depicts an aerosol in which all of the sizes measured contain a population of less hydrated, hysteretic aerosol. For most of the sizes, there is also a fraction of more hydrated, hysteretic aerosol. In addition, there appears to be a fraction of non-hysteretic aerosol, implied by comparisons between the hysteretic mode of the DF (or EF) results 
23 Nov. 2007, 14:36 - 16:16 (LT)

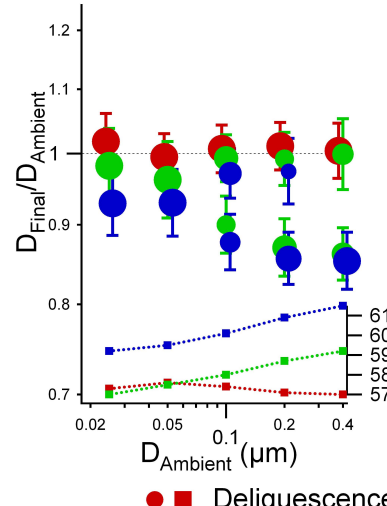

7 Dec. $2007,06: 06-07: 46($ LT $)$

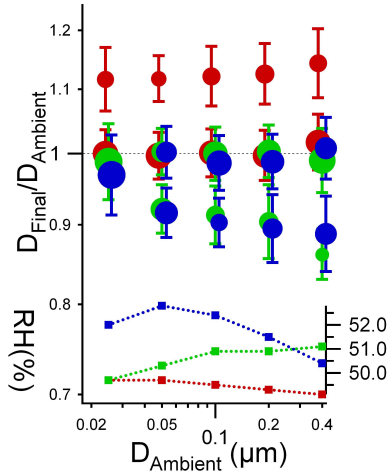

27 Jan. 2008, 20:40 - 22:20 (LT)

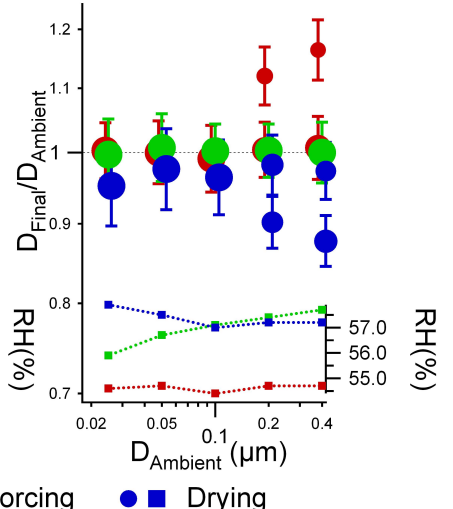

Fig. 7. Results of three AS-TDMA full measurement cycles from the winter campaign. Details of plot formation are given in the caption of Fig. 6.

and the near unity mode in the results of the EF (or DF) that contains its aerosol fraction. A residual non-hysteretic fraction is inferred because the number concentration (the size of the point) of the hysteretic mode does not fully account for the complementary non-hysteretic mode. A lack of certainty rises from the time separation between the measurements. The final plot illustrates a case in which only a less hydrated, hysteretic fraction exists in the larger sizes. In this case, there appears to be some residual water in the less hydrated state. This is apparent from the difference in size between the EF and Drying process modes near unity.

The variety of results from the winter campaign defied easy typecasting (as the summer). Though the number of variations in the 432 recorded measurement cycles prohibits full treatment in this format, a few characteristics may be noted. First, the multi-modal behavior apparent in the three winter plots above was fairly typical. This contrasts with the summer results that were more typically monomodal. A second contrast, also treated in the result summaries, is the general lack of residual water in the less hydrated state of hysteretic aerosol during the winter. Finally, it should be noted that the simultaneous appearance of more- and less-hydrated states seen in the second of the winter plots was a regular feature. It is apparent in the winter time series and its frequency is illustrated in Fig. 12 as described in Sect. 3.3.3. It is a surprising feature and deserves some consideration.

$\mathrm{RH}$ history is a determinative factor of hydration state. In conjunction with this, the coexistence of a more and less hydrated state is interesting, if not problematic. Though it is beyond the scope of this work to rigorously treat this question, two possibly complimentary mechanisms can be suggested. First, it might be explained by differences in efflorescent and deliquescent transition points within the aerosol populations. A second explanation is mixing of parcels with different $\mathrm{RH}$ histories. This question will appear again in the second of the following time series. The AS-TDMA results will not be suf- ficient to answer this question but more context is provided in that format.

\subsubsection{Time series}

This section discusses Figs. 8 and 9: two time series of ASTDMA results from the course of several days during each study period. The plots differ from those above primarily in that the ordinate is time rather than ambient size, now depicted by color. For the sake of clarity only two sizes, 0.05 and $0.2 \mu \mathrm{m}$, are shown. In addition to the ambient $\mathrm{RH}$, these time series show the controlled RH to illustrate the proficiency of the instrument at reproducing ambient levels.

This format neatly depicts transitions in the hydration characteristics of ambient aerosol. The following examples illustrate the effect of varying RH on both the detection of hysteresis and the hydration state observed. However, it must be emphasized that the length of time considered is sufficient to include significant variation in the aerosol. The treatment of concentration in these plots is deceptive as it is normalized by the total AS-TDMA scan concentration (i.e. each resultant size distribution is normalized to unity total concentration). This emphasizes the contribution of individual modes but obscures aerosol population dynamics and comparative concentration. These cautions notwithstanding, the following plots serve well to highlight interesting variety in hydration behavior.

A typical time series from the summer campaign is shown in Fig. 8. It includes all measurements made over a 2.5 day period. It features the diurnal RH cycles that were shown, in Fig. 3 of the seasonal characterizations, to typify the period. A portion of the Drying process results (in blue) mirror the ambient RH, indicating a significantly hygroscopic aerosol fraction. The larger sizes are generally bottommost, or most hygroscopic: an attribute noted in the measurement cycle plots above. The DF results (in red) are consistently 


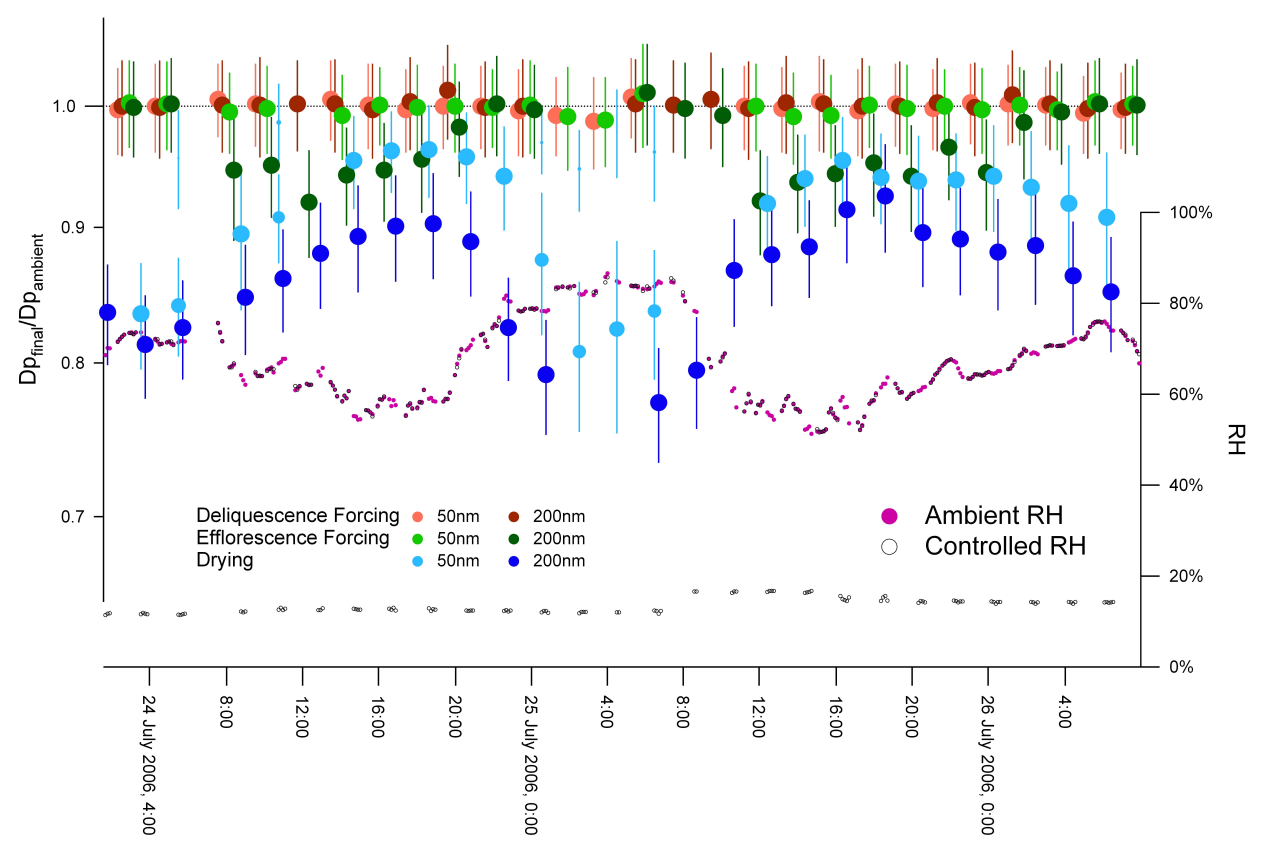

Fig. 8. A time series of AS-TDMA measurements from the summer campaign. The point and error bar markers follow the convention described in Sect. 2.3 .

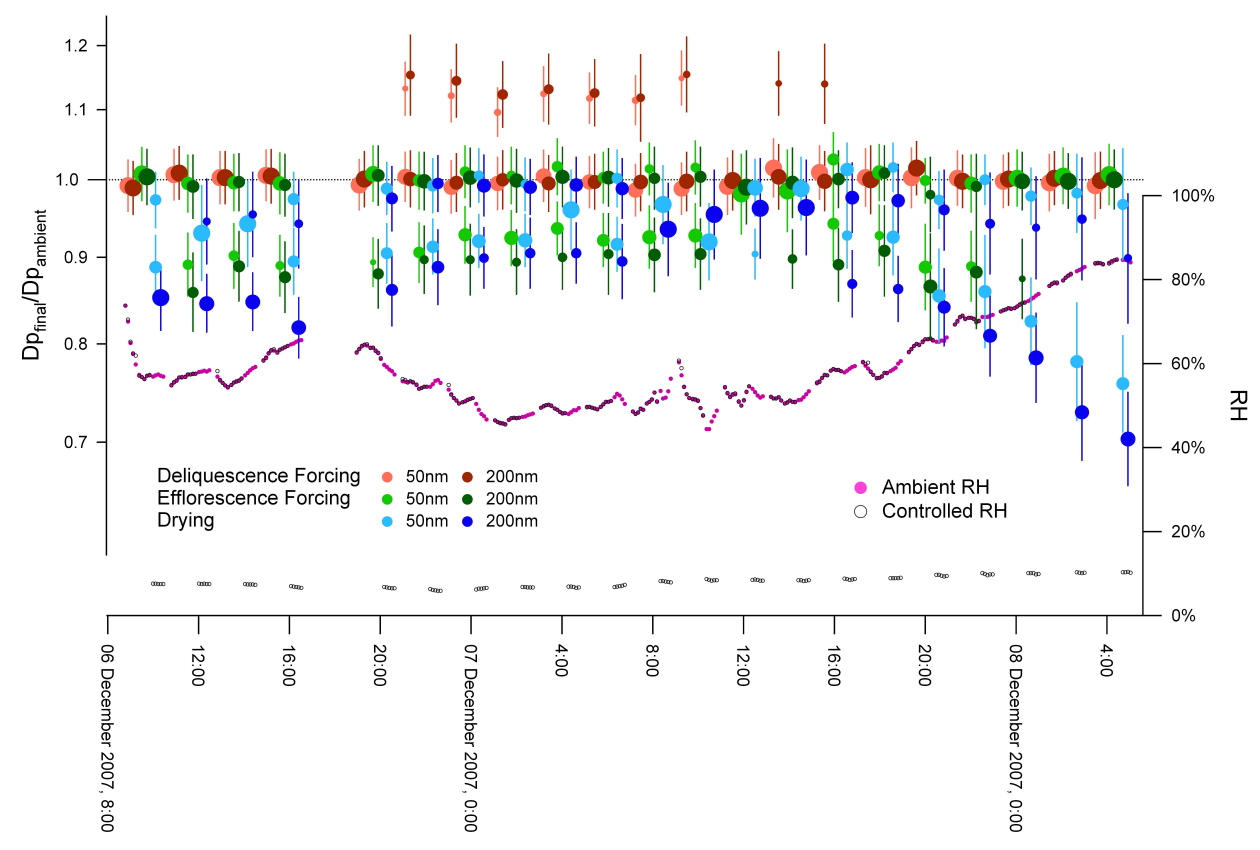

Fig. 9. A time series of AS-TDMA measurements from the winter campaign. The point and error bar markers follow the convention described in Sect. 2.3.

near unity in coherence to the study-long failure to detect any less hydrated ambient state. The EF results vary with $\mathrm{RH}$. During the nights and mornings when the RH is high, the EF results remain near unity. As RH decreases through the afternoons, a portion of the EF results begin to indicate water loss. This suggests that a portion of the aerosol does exhibit hysteretic hydration behavior, but that the deliquescence threshold is crossed as the RH increases beyond the domain of hysteresis. 
As noted, this was a typical case for the summer. Most generally, some portion of the ambient aerosol would exhibit hysteresis when RH levels fell. The transition point and portion of the aerosol involved varied. Detecting that transition point is a task better suited to the RH-scanning H-TDMA. Thus, the primary unique AS-TDMA result from the summer is quite monotonic: whenever hysteresis was detected, the aerosol was found in the more hydrated state.

This was not so during the winter. Figure 9 depicts a case study chosen from the winter campaign that shows changes in the hydration state detected during a 2 day period. Three related aspects of hydration state variability highlighted in this case study are interesting, if not surprising. The first is the variability of the detected ambient hydration state despite local RH remaining within the RH domain of hysteresis. The second is the continuous variation of the fraction in each state, evident from the changes in the relative concentration of less-hydrated particles. The final feature is that only part of the hysteretic fraction at each size is ever detected in a less hydrated state.

Before discussing these more subtle points, one additional feature should be noted. This plot shares with the summer case study a descent of ambient RH into and out of the RH domain of hysteresis of some fractions of the aerosol. This occurs during the first and second measurement cycles, shown at 09:00 LT, 6 December 2007; with hysteresis detected only during the $0.4 \mu \mathrm{m} \mathrm{EF}$ measurement (not shown) in the first and the detection of a hysteretic fraction of all sizes in the second. Near the end of the case study, ambient $\mathrm{RH}$ rises out of the hysteresis domain with no non-unity EF or DF results appearing after 00:00, 8 December. Unlike the summer case study, RH also appears to fall below the domain of hysteresis, with little hysteresis detected in the measurement after 12:00, 7 December.

The first of the points listed above, the variability of hydration state within the apparent $\mathrm{RH}$ domain of hysteresis, is illustrated best by the appearance and disappearance of less hydrated fractions in the results. These occur while RH is falling and rising, respectively. Yet, though $\mathrm{RH}$ continues to fall (and rise), a hysteretic fraction continues to be detected. This indicates that the endpoints of the hysteretic domain, the RH's for irreversible efflorescence and deliquescence, are not reached. In the case of disappearing less hydrated states, the transition occurs well in advance of the apparent deliquescence RH indicated by the cessation of hysteresis detection at 01:00, 8 December. Similarly, local ambient RH falls significantly following the first appearance of the less hydrated state before reaching the supposed efflorescence RH immediately following 12:00, 7 December.

During this period of falling RH after the first appearance of less hydrated, hysteretic ambient aerosol, the second interesting feature is evident. The fraction of hysteretic ambient aerosol determined as less hydrated continues to increase with falling RH. Though not evident, the total hysteretic fraction for the smaller sizes increases during this time, but the
$0.2 \mu \mathrm{m}$ hysteretic aerosol fraction remains constant. For that size, it appears that the hysteretic population is conserved while a portion of more hydrated aerosol transitions to the less hydrated state. However, at no point do all hysteretic aerosols occupy a less hydrated ambient state. This third feature is broadly evident, but is most surprising following the apparent fall of RH below the domain of hysteresis at 12:00, 7 December.

Before speculating further about these features, some consideration is given here to the typicality of this case. During the winter campaign the detection of less hydrated, hysteretic aerosol most often involved a similar apparent transition from a fraction of metastable aerosol as RH fell. The exceptions were 2 cases in which the $\mathrm{RH}$ fell lower than the ostensible efflorescence point. When $\mathrm{RH}$ rose back into the hysteretic domain, the hysteretic fraction was generally detected in a less hydrated form. However, the gradual increase, with falling RH, in the portion of hysteretic aerosol in a less hydrated form depicted in the case in Fig. 9 is typical. Similarly, the gradual reversion of the hysteretic fraction to a metastable state with increasing RH is typical. For both transitions, the noted feature that they occur while local $\mathrm{RH}$ remains within the bounds of efflorescence $\mathrm{RH}$ and deliquescence RH is consistent in all observed cases. Also, these transitions all proceeded through a regime in which more- and less-hydrated states were simultaneously detected. In some cases, as RH fell sufficiently low, the entire hysteretic aerosol fraction was eventually found in a less hydrated state. Yet, this complete reduction in the portion of metastable aerosol progressed gradually with falling $\mathrm{RH}$.

This case study is thus largely typical. One additional feature should be covered, springing from the two exceptional cases mentioned above in which RH apparently fell below the domain of hysteresis. The notable feature of these cases is that the apparent efflorescence RH (determined by the cessation of hysteresis detection with low $\mathrm{RH}$ ) is near the $\mathrm{RH}$ at which the meta-stable fraction disappears: much nearer, particularly, than the apparent deliquescence RH (detected in the case above near 00:00, 8 December 2007) is to the RH at which a less hydrated, hysteretic fraction is no longer present in the case above and all others considered.

Taken together, these characteristics suggest a significant degree of mixing and a significant divergence between the local RH and the RH history of the particles. The bias discussed in the previous paragraph suggests that the RH history is more often perturbed higher than lower. This bias is likely due to the characteristic profile of increased $\mathrm{RH}$ with height in active boundary layers. Finally, the ridge-crest location of the measurement facilites should be recalled, adding complication. In conclusion, the results depicted in this case study suggest that ambient hydration states are quite dynamic, highlighting the need for comparative studies between the various model treatments of hydration state and in situ measurement. 


\subsection{Study summaries}

This section features a variety of plots summarizing ASTDMA results from the two measurement campaigns. It begins with a set of simple summaries of the AS-TDMA DF and EF process results. The next element treats the seasonal contrast in water content of the less hydrated state of hysteretic aerosol. Finally, two sets of plots illustrate relations between the observance of hysteresis and time of day, $\mathrm{RH}$ and the composition measurements discussed above.

\subsubsection{AS-TDMA deliquescence forcing and efflorescence forcing process results summary}

The frequency plots in Fig. 10 simply summarize the DF and EF AS-TDMA measurements for each ambient size during the two measurement periods. In keeping with convention, the DF process results are shown in red and EF results in green. The counting is based on the modes characterized by log-normal curves. Each mode is counted as the fraction it contributes to the total concentration in its containing size distribution. Each measurement is given a total weight of 1 . The grey bars indicate the fraction of non-hysteretic results. These are calculated based on the portion of aerosol in each measurement not accounted for by a hysteretic DF or EF process mode. In effect, they are $100 \%$ less the sum of the bars shown in red and green.

Two major features appear in the summer results. The first is the lack of less hydrated, hysteretic aerosol, indicated by no non-unity DF results. The second is the variation with size in the portion of more hydrated hysteretic aerosol. A maximum frequency of detection occurs in $0.2 \mu \mathrm{m}$ measurements. This corresponds with the size variation noted in the single measurement cycle results shown above. The winter results stand in contrast to the summer on two points: more frequent detection of hysteresis and variety in the hydration state detected. Similar to the summer, the winter results also show variation with size. Most frequent detection of hysteresis occurred with the larger sizes. Interestingly, there is little size variation in the fraction of less hydrated states detected.

\subsubsection{Residual water}

The charts in Fig. 10 summarize only the differences between hydration states. However, as indicated in the discussions of the measurement cycle examples, there was a seasonal contrast in the amount of water contained in the less hydrated state. This is based on the difference between the least hydrated state and the Drying process results.

The formations of this and the remaining charts in this section rely on the qualification of each mode (as characterized by log-normal curve fits) in each EF and DF process measurement as either hysteretic or non-hysteretic. This qualification is discussed in the methodology appendix (Appendix A4). As with the previous charts, modes are counted as the fraction they contributed to their containing size distribution.

The residual water in the less hydrated state is quantified here by the ratio of final diameter following the EF process and following the Drying process. Figure 11 contrasts this result for the summer and winter campaigns. Only the measurements in which hysteresis is detected are counted. Also, the hygroscopic growth model described in the methodologies section was applied to simulate equivalent results at $60 \% \mathrm{RH}$. This corrected for the additional bias introduced by variation in the RH at which hysteresis occurred, a concept more fully treated in the next sub-section. As previously noted, the difference between the post-EF and post-Drying sizes was generally larger during the summer. This is indicated by more common occurrence of higher ratios.

\subsubsection{Relative humidity and time of day dependence of hysteresis detection}

Figure 12 contains frequency plots of the detection of hysteresis versus time of day and versus $\mathrm{RH}$. The formation of these relies on the hysteresis qualifications already discussed and counts each measurement as a unit with multiple modes as their appropriate fraction. The frequency is normalized by the total number of measurements, so that each bar indicates the fraction of all measurements (not only those detecting hysteresis) of each type (EF or DF) that both has the characteristics of the bin and is categorized as hysteretic. Because of this, the bars do not sum to 1 , but to the total fraction of hysteresis detection. For comparison, the total fraction of all measurements that were conducted under the bin conditions are also plotted in the RH charts using the right axis. Finally, the darker portion of the bars in the winter RH chart indicates the fraction that was detected in coincidence with the other hydration state, mentioned in the case study discussion.

The major feature of the summer RH chart is the lack of hysteresis at high RH. This also appears in the winter chart, but the truncation occurs at higher RH levels. This cutoff corresponds roughly to an average $\mathrm{RH}$ for deliquescence during the season and the higher deliquescence $\mathrm{RH}$ in the winter is in accordance with the estimates from composition illustrated in Fig. 4. The summer and winter charts also contrast in overall frequency of hysteresis. But the greatest contrast lies in the detection of less hydrated, hysteretic aerosol during the winter.

The winter RH based hysteresis frequency chart illustrates a strong relationship between RH level and hydration state, with less hydrated states being more frequently detected at low RH. It also shows the predominance of more hydrated over less hydrated states. Reasons for this predominance can be suggested. First, it is evident from the dashed distribution of total measurement frequency that ambient RH more often exceeded the deliquescence point than it fell below the efflorescence point. In addition, as discussed concerning the winter case study, there appears to be a bias in RH history versus 

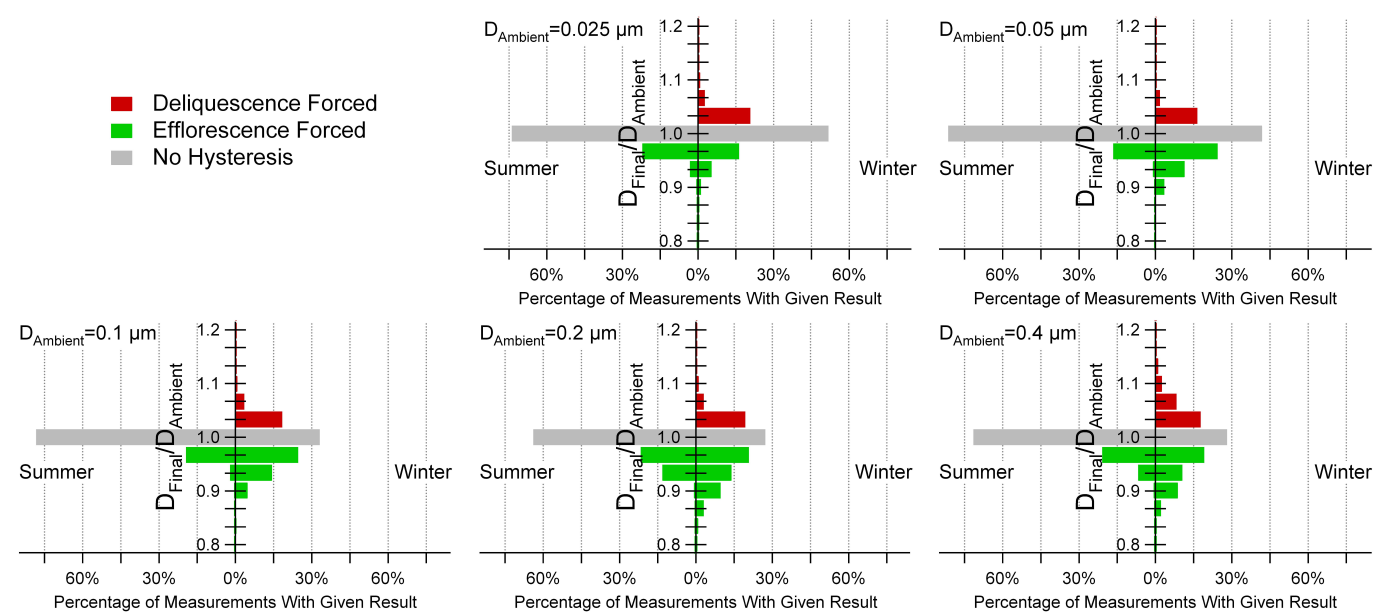

Fig. 10. Deliquescence and efflorescence forcing measurement summaries for the summer and winter campaigns.

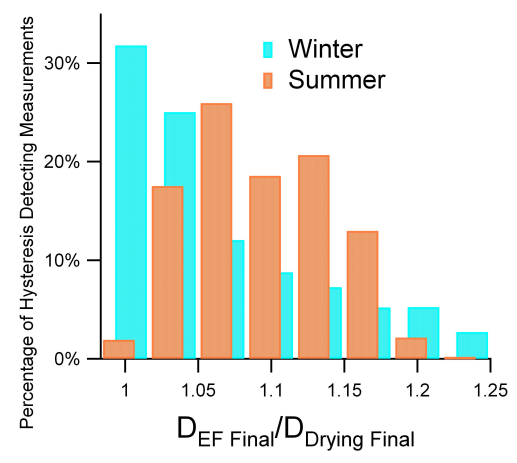

Fig. 11. A frequency plot illustrating the variation in residual water content of the less hydrated state between the two studies.

local, ambient RH history toward higher RH. This would follow from active boundary layer circulations. However, these suppositions need further work and treatment of local atmospheric dynamics to be confirmed.

From comparisons of the dashed distribution of total measurement frequency of each season it is evident that RH fell lower in the winter than in the summer. Yet it is interesting that the detection of less hydrated, hysteretic aerosol in the winter often occurred at RH levels reached during the summer. This could be the result of likely seasonal differences in the efflorescence point, similar to the variation in deliquescence RH roughly evident in the charts. But an additional factor could be local dynamics. As illustrated in the depictions of diurnal RH and temperature in Fig. 3, in the summer RH generally fell in conjunction with daytime heating. Thus, the periods of low RH were likely associated with active boundary layers. This in turn would suggest that the RH history is driven by boundary layer circulations with accompanying lofting, cooling and increased RH. In contrast, the weak diurnal variation illustrated for the winter period both in the case study (Fig. 9) and Fig. 3 seems less susceptible to this bias.

The lower set of charts shows the time-of-day dependence of hysteresis detection. The results are strongly anticipated from RH dependence above and RH and temperature characterizations in Fig. 3. Thus the summer plot indicates a strong diurnal cycle. While the winter plot shows a cycle as well, it is weaker and hysteresis was detected at all times of day. No total measurement frequency plot is included in the time-ofday charts to avoid confusion. It would be equivalent to the time-of-day distribution shown in Fig. 3 that has the major characteristic of nightly depression due to the inoperability of the instrument at very high RH. However, as the RH plots in Fig. 12 show, it is highly unlikely that hysteresis would have been detected during these periods. Otherwise, measurements were conducted with nearly uniform frequency. Thus, the missing measurements should not be assumed to contain a similar proportion of hysteresis detection as by-eye comparisons would suggest.

\subsubsection{Hysteresis detection versus filter composition results}

In this final sub-section of results, the relationship between the filter composition measurements and the detection of hysteresis is considered. This comparison is slightly compromised by limitations on the size and time resolution of filter based measurements. However, beyond being the best available composition data, these filter results are comparable to the nation-spanning IMPROVE network. This greatly increases the possible applicability of constructive comparisons.

The AIM model deliquescence predictions shown in Fig. 4 are the basis of this comparison. Efflorescence is not treated for a variety of reasons: first, the determination of efflorescence RH thresholds is significantly more difficult, being 


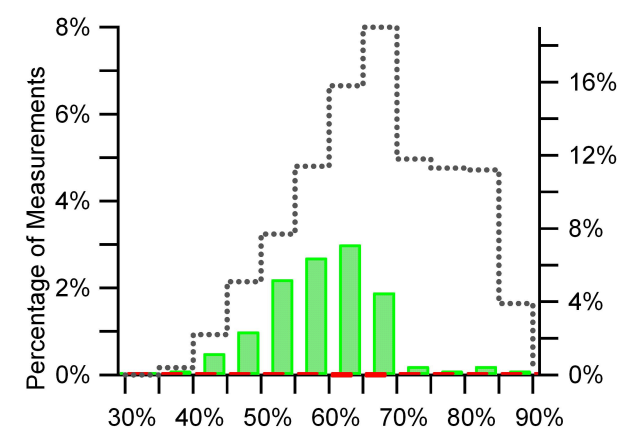

$\mathrm{RH}$

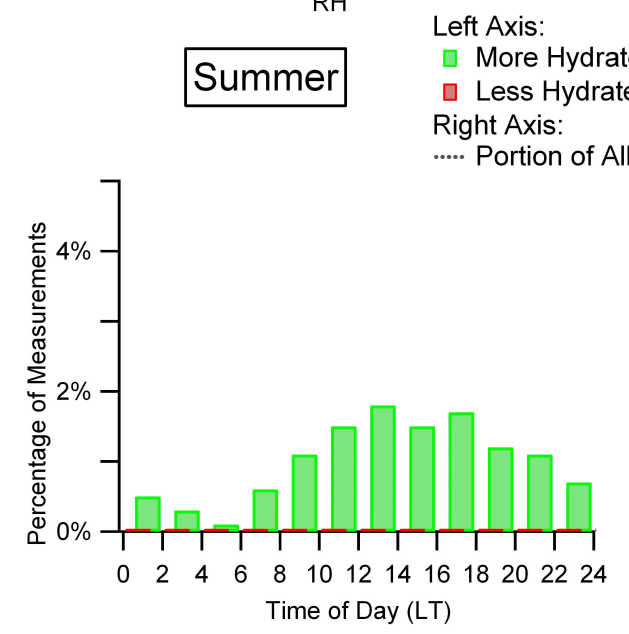

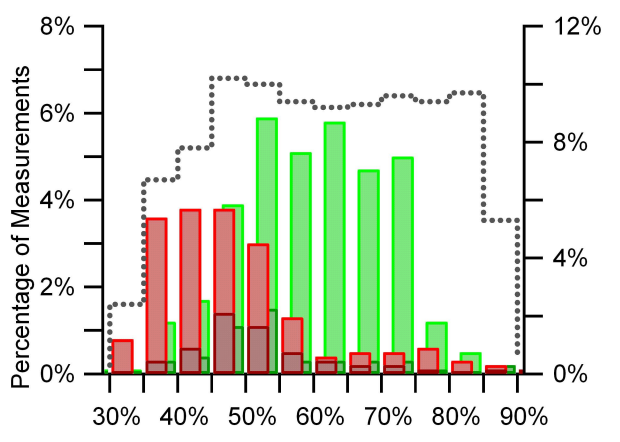

$\mathrm{RH}$

Winter

State Detected

$$
\text { Measurements in Bin }
$$

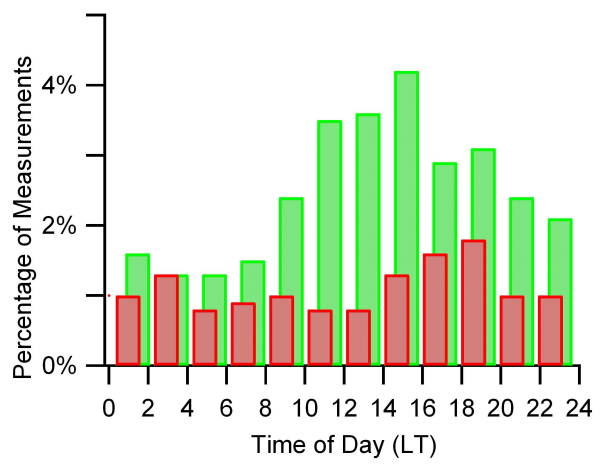

Fig. 12. Frequency plots of hysteresis detection versus RH and time-of-day for summer and winter campaigns. The darker portion of the bars in the winter RH plot indicates fractions detected in coincidence with the alternative hydration state.

dependent on solid phase nucleation kinetics rather than bulk thermodynamics (as deliquescence). Consequently, models predicting this behavior are not as readily available. Secondly, full efflorescence and cessation of hysteresis detection rarely occurred in these studies. Therefore, this comparison focuses on the deliquescence transition as predicted by composition and indicated by cessation of hysteresis detection in AS-TDMA measurements.

Figure 13 depicts the relation between predicted deliquescence $\mathrm{RH}$, ambient $\mathrm{RH}$, and hysteresis detection and was formed as follows. First, the filter composition results were interpolated to all of the measurement triplets (DF, EF and Drying process) from the intensive periods of each campaign. The interpolation was based on the time each measurement occurred and ascribing the daily filter results to 12:00 p.m. From these compositions the expected full dissolution RH was calculated for each AS-TDMA measurement using AIM as described in the first portion of the results section. Each measurement was then plotted as a point in the charts of Fig. 13 with coordinates of the expected full dissolution RH and the average ambient RH during the measurement. Next, the point was shaded based on the fraction of measurements with similar RH coordinates that detected more- or less-hydrated (or either), hysteretic aerosol, depending on the plot. The local hysteresis frequency was calculated for each point using the nearest 80 measurements under a simple distance on the ambient $\mathrm{RH}$, calculated dissolution RH coordinates.

With this formation, if the ambient aerosol deliquescence RH is consistent with expectation from composition, hysteresis should be detected only and universally at coordinates below the 1:1 bisection. This is not the case. Focusing on the top plot, it is evident both that hysteresis is detected beyond expected deliquescence RH levels and that hysteresis is not consistently detected below the expected deliquescence levels. This result is somewhat anticipated by the illustrated size dependence of hysteresis detection already discussed. Beyond this, however, there is a surprisingly persistent threshold for hysteresis. The less hydrated state detection indicated does not form as distinct a feature, a consequence of the deliquescence basis of the plot. 


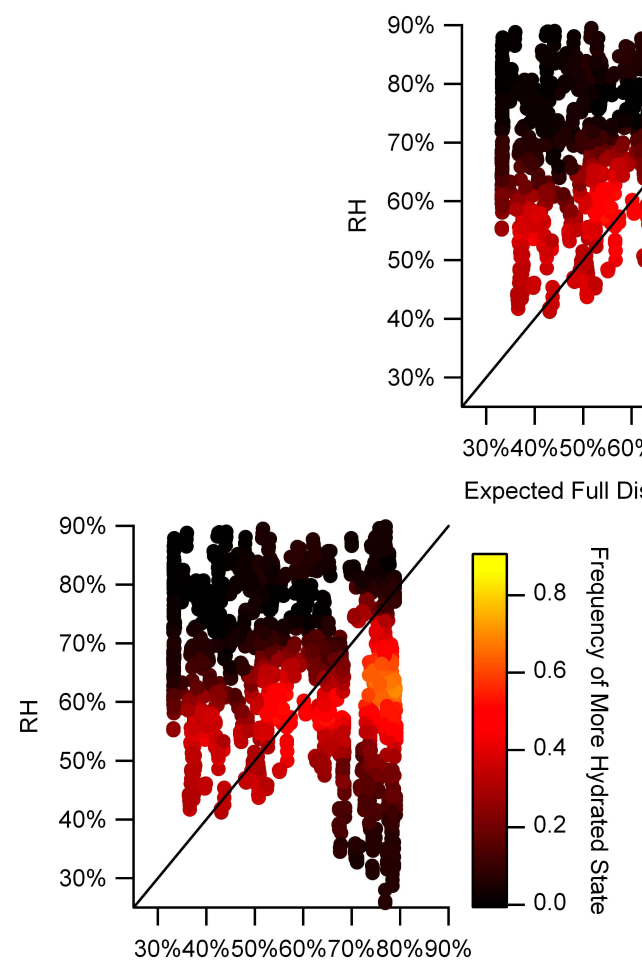

Expected Full Dissolution RH

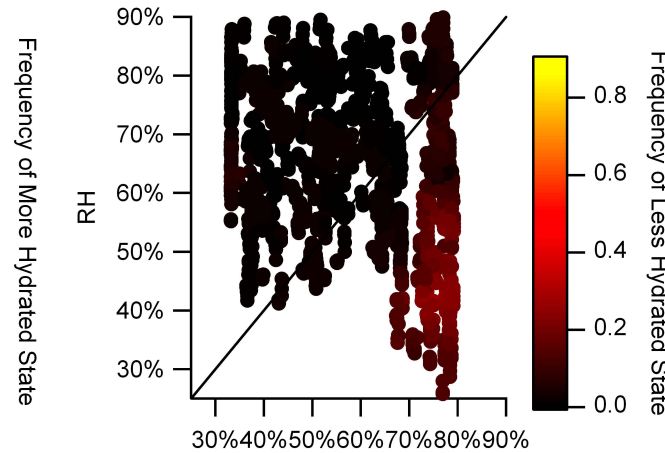

Expected Full Dissolution RH

Fig. 13. Hysteresis detection versus the ambient RH during measurement and filter determined composition based estimates of deliquescence RH. The upper chart indicates frequency of any hysteresis detection, while the lower two treat each state individually. Every measurement from both campaigns is plotted based on the interpolated AIM estimate of dissolution RH and ambient $\mathrm{RH}$ at the time it is conducted. The frequency at each point is calculated as the fraction of the nearest 80 measurements that detect either (or both) hydration state, depending on the plot.

\section{Conclusions}

The findings presented in the paper provide a new perspective into the behavior of atmospheric aerosol. Primary among the unique elements of this investigation was the positive detection of both more- and less- hydrated forms of hysteretic ambient aerosol. For the GRSM project, this detection was strongly biased by season, with less hydrated states detected only during the winter project. We have illustrated that this was likely driven both by seasonal variation in $\mathrm{RH}$ and seasonal variation in aerosol composition. Variability in the detection of both states during the winter project allowed us to examine the relationship between local conditions and ambient hydration state. This relationship was shown in case studies to be complex and dynamic. These case studies contained several notable features such as the coincident detection of more- and less- hydrated states within the results of a single measurement and the continuous variation in the fraction in these states even as local $\mathrm{RH}$ remained within the domain of hysteresis.

Three additional results from the AS-TDMA concerning aerosol hydration characteristics that did not depend on its unique capabilities have local significance. First, the appar- ent RH levels for phase transitions varied between the two seasons, with higher $\mathrm{RH}$ thresholds for both efflorescence and deliquescence apparent during the winter. Second, the less hydrated state of hysteretic aerosols detected during the summer contained significant residual water, opposed to their nearly dehydrated winter counterparts. Finally, detection of hysteresis showed dependence on size, especially during the summer campaign.

In the presentation of these results, some considerations of future directions have already been given. Primarily, the descriptions indicated the desirability of complementary treatments of local dynamics to facilitate the understanding of observed phenomena. These included the continuous variation of the hydration state of the hysteretic fraction noted in the winter case study and the bias of toward the more hydrated state indicated in the summary of RH dependence. Further, while the AS-TDMA has been demonstrated to retrieve the ambient hydration state of aerosol, the ultimate objective is to achieve this determination with models. Future work would therefore be greatly enhanced by the incorporation of modeling efforts. Within the current project, a more focused assessment of the implication of these results and those from recent and future campaigns at Mount Rainier and Acadia 
US National Parks for visibility degradation is forthcoming. While the Great Smoky Mountains findings clearly show that not all particulate sulfate is hydrated, they also demonstrate the importance of local conditions for that result and underscore the need for measurements in divers environments. In conclusion, the AS-TDMA results from this study provide a first look at the variability of ambient aerosol hydration state. Though future efforts are needed to close the remaining gaps in our understanding of this behavior, we believe the AS-TDMA configuration can contribute uniquely to this endeavor.

\section{Appendix A}

\section{AS-TDMA data treatment}

AS-TDMA results take the form of size distributions, as illustrated on the right side of Fig. 2. While this form is adequate for simple evaluations, additional procedures were applied to refine the results and to facilitate more complicated analysis. These are described in the elements of this appendix titled Log-Normal Curve Fits, Mode Correlation, Hygroscopic Growth Model Use, and Qualification of Hysteresis and Scan Offset. Two final elements cover the treatment of multiply charged particles and AS-TDMA calibration.

\section{A1 Log-normal curve fit}

The resultant size distributions were produced by inverting the response of the CPC with respect to the final classifier only. This causes the signal from the initial, ambient classifier to remain. This signal is the natural, roughly triangular distribution actually transmitted. Thus, when no change is effected by the inter-classifier processes, the final size distribution accurately depicts this signal. Some groups using TDMA have utilized this signal as a kernel for a second inversion (Gysel et al., 2009); however, additional sources of noise and signal breadth make this technique less applicable to AS-TDMA results. One source of mode broadening is compositional heterogeneity, which causes a blurred response to inter-classifier processes. Also, occasional deviations between ambient and controlled RH levels can generate additional broadening and variation in the location of the effective "no change" size. For these reasons it is difficult to fully invert the AS-TDMA results using traditional methods. Yet, because the size responses of the AS-TDMA processes are often small (roughly analogous to classic hygroscopicity TDMA measurements at low $\mathrm{RH}$ ) and often involve responses in minor populations of the aerosol, it is imperative to refine the results as much as possible.

To this end, a constrained Levenburg-Marquardt optimization routine was used to fit the data with the sum of up to 4 log-normal modes. An application of this technique is demonstrated in the lower left of Fig. 2 for a set of measure- ments made during the winter portion of this study. Each lognormal mode is characterized by its relative contribution to total concentration, geometric mean diameter and geometric standard deviation. In effect, this method serves as a pseudoinversion. Each mode ideally captures the response (both broadening and translation) of various fractions of the initial kernel distribution to the inter-classifier processes. The adaptive nature of this treatment to mode location and breadth make it a good choice for AS-TDMA measurements. Inevitably, there are difficulties that arise from poorly resolved modes. In these cases, the optimization results can be nonunique and unstable. The optimization routine used may also be sensitive to choices of initial guess and this becomes truer in these cases. However, by utilizing systematic and welltuned heuristics for the initial guesses and the constraints on the mode parameters these effects can be reduced. Non-ideal cases were observed only occasionally; more frequently, the modes were clearly resolved. Overall, though this technique is not rigorous, its systematic application provided consistent results. These results are also ideal for application of the experimental principles of the AS-TDMA. For the DF and EF processes, the criteria of size change can be applied to the mean size of each mode in comparison to the mean size selected by the first classifier. Additional steps are needed to utilize the Drying process results, but they are greatly facilitated by this characterization of the data.

\section{A2 Mode correlation}

The Drying process measurements are made to recover the total amount of water in both the ambient hydration state and final, processed hydration states detected in the DF and EF measurements. To apply the Drying process results, the modes resolved in the DF and EF measurements must be correlated to the modes in the Drying process results that contain those fractions of the aerosol. Moreover, to repair deviations in the synchronization of the ambient and controlled $\mathrm{RH}$, it is useful to correlate the modes detected in the EF and DF processes. The final product of these mode correlations is a tabulation of all the distinct fractions of the aerosol that are resolved by the three processes. The difficulty achieving this objective ranges from trivial when the aerosol is internally mixed (and therefore characterized by single modes) to impossible when too many modes are resolved in each scan. To clarify the nature of this objective and to motivate the routine and simplifications finally used to approximate it, the correlation process for the measurements depicted in the lower right of Fig. 2 is elaborated.

The correlation of modes in DF and EF results is simple. Any fraction of the ambient aerosol that changes size during one of these processes is assumed to not change size during the other, i.e. a particle does not simultaneously have both a more- and less- hydrated possible state. This requires the assumptions that there are no intermediate ambient hydration states and that no change in the hydration state occurs 
between the two process measurements. In the results depicted in the lower right of Fig. 2, the DF process resolves a fraction of the aerosol initially in a less hydrated state. Because it is initially less hydrated, that fraction is assumed to be included in the mode that does not change size in the EF process results. Similarly, the fraction found to be initially in a more hydrated state by the EF process is assumed to contribute to the mode at unity size ratio in the DF results. Note that only a subset of the aerosol displayed hysteresis. Less than half of the aerosol is in each of the hysteretic modes, implying a fraction of non-hysteretic aerosol in the modes at unity size ratio in both the DF and EF results. In this way the EF and DF results together resolve both the hysteretic fractions and the total non-hysteretic fraction.

The further correlation to the Drying process results is more problematic. The first two processes have a clear relationship that can be used to compare them. This is not the case with the Drying process. Between it and the DF and EF processes only a weak and often inconclusive relation exists, consisting of a system of constraints on possible water content and the conservation of total aerosol fraction between the three measurements. Consider the case above. The most concrete constraint exists for locating the fraction known to be initially in a more hydrated state. Those particles are known to contain at least the amount of water that was lost as they transitioned to their less hydrated state in the EF process. Thus, that fraction is known to correlate to a fraction in the Drying process results that has lost at least so much water. In the case above, there is a mode that fills this criterion. Locating the aerosol fraction shown to be initially in a less hydrated state by the DF process is less constrained. During the summer measurement period, the amount of water retained in the less hydrated state of hysteretic aerosol was occasionally near $50 \%$ of the amount contained in the most hydrated state. Yet no indication of the residual water content is given by the EF and DF process results alone. In the case above, some headway can be made by assuming the hydration characteristics of the two hysteretic fractions are similar, hydration state aside. This would imply little residual water content in the less hydrated state because the loss of water by efflorescence and by drying is similar for the fraction of the aerosol initially in its most hydrated state. This would also determine the aerosol fraction resolved by the DF process as hysteretic and in a less hydrated state to be in the Drying process mode that shrinks less upon drying. These assumptions are strengthened by the fact that the aerosol fraction in the Drying process mode with the greatest reduction in size is almost entirely accounted for by the most hydrated ambient aerosol fraction resolved in the EF process measurement. Therefore, that Drying process mode could not contain the entire ambient less hydrated hysteretic aerosol fraction. In this way, the conservation of aerosol fraction can be used to apportion the remaining non-hysteretic population resolved by the EF and DF process comparison. Indeed, for this fraction of the aerosol no other constraint exists.
The above case approaches the limit of reasonable correlation. If an additional mode had been resolved in the Drying process results (a distinct possibility, as the non-hysteretic fraction is unconstrained by the EF and DF results) the apportionment might have been impossible. However, the vast majority of cases were readily correlated, consisting of two or fewer modes from each measurement. In addition, the primary objective is to determine the dry size of the modes resolved in the EF and DF scans. A multiplicity of modes in the Drying process results may depict a variety of externally mixed aerosol types, but these do not necessarily concern this study. Thus, to retrieve an approximation of the dry size in cases where the explicit correlation of aerosol fractions is impossible, the Drying scans were constrained to be fit by at most two major modes. The correlation to these Drying process modes assumed that all hysteretic particles in the most hydrated state were accounted for by the Drying process mode that contained the most water initially, and the ambient less hydrated hysteretic aerosol fraction was entirely contained in the Drying process mode that contained the least water. While this treatment is imperfect, the error it introduces is limited. Also it converges with the explicit consideration described above, only introducing error in the minority of cases that contain intractably many modes.

These correlations result in a set of descriptions of the various resolved fractions. For each fraction, the characteristic dry size, the ambient size, the size of the most hydrated state it could occupy, and the size of the least hydrated state it could occupy are known. The ambient hydration state can be determined by comparisons between known hydration state sizes and the ambient size. The water content of each state is known by comparison with the dry size. The resolved and correlated populations thus make the ideal result of the ASTDMA operation, allowing full and easy comparison of the three measurements.

\section{A3 Hygroscopic growth model use}

It should be recognized that ambient RH did vary sufficiently for the RH during each of the three processes in a measurement cycle to be significantly different. This inconsistency is partially removed by using a hygroscopic growth model to predict from the retrieved values the equivalent response at a standard RH. This treatment has the advantage that it also partially removes the effect of discrepancies between the ambient $\mathrm{RH}$ and the controlled $\mathrm{RH}$ intended to mirror ambient levels. While this control was mostly excellent, an additional complication was caused by lag between the internal temperature of the ambient classifier column and the actual ambient temperature. The ambient RH probe did not have this limitation. Thus, the controlled RH of the sample stream entering the final classifier was accurate, but sometimes differed from the $\mathrm{RH}$, perturbed by temperature lag, in the ambient classifier. This perturbation was small, but did decrease the accuracy of detection of hysteretic aerosol near phase transition 
Table A1. AS-TDMA RH probe calibration elements.

\begin{tabular}{llll}
\hline & Process & Result & Reflected in Size Change \\
\hline \multirow{2}{*}{$\begin{array}{lll}\text { Initially Metastable } \\
\text { Fraction }\end{array}$} & $\mathrm{DF}$ & little or no change & $\Delta \mathrm{RH}, \Delta \mathrm{Q}_{\text {sheath }} / \mathrm{HV}$ \\
& $\mathrm{EF}$ & shrinking & $\mathrm{RH}$ \\
& Drying & shrinking & $\mathrm{RH}_{\text {Ambient }}, \Delta \mathrm{Q}_{\text {sheath }} / \mathrm{HV}$ \\
\hline \multirow{2}{*}{$\begin{array}{l}\text { Initially Crystalline } \\
\text { Fraction }\end{array}$} & $\mathrm{DF}$ & growth & $\mathrm{RH}_{\text {Controlled }}, \Delta \mathrm{Q}_{\text {sheath }} / \mathrm{HV}$ \\
& $\mathrm{EF}$ & little or no change & $\Delta \mathrm{Q}_{\text {sheath }} / \mathrm{HV}$ \\
& Drying & little or no change & $\Delta \mathrm{Q}_{\text {sheath }} / \mathrm{HV}$ \\
\hline
\end{tabular}

RH levels. When the aerosol was not near phase transitions, this perturbation is also corrected by the application of a hygroscopic growth model. The limitations of this method lie in its inability to treat phase transitions, only modeling continuous variation of water content with changes in RH. The hygroscopicity model utilized for these manipulations treated the aerosol as a single component salt solution surrounding an inactive "core". The water activity and surface tension of the solution were calculated using parameterizations from Tang (Tang and Munkelwitz, 1994; Tang, 1996; Tang et al., 1997). The prediction of the equivalent measurement results for an aerosol for an arbitrary, alternative ambient RH was also used to standardize all measurements to a single RH as a means of normalizing the variation in water content due to RH.

\section{A4 Qualification of hysteresis and scan offset}

Though these attempts to remove $\mathrm{RH}$ and temperature driven deviations in the measurements greatly improved the results, some noise remained in the AS-TDMA measurements. A final refinement of the results was conducted based on the position of non-hysteretic modes in the EF and DF results. These modes should posses a unity size ratio, but occasionally were offset. This was most likely due to too rapid shifts in ambient $\mathrm{RH}$ and temperature for either the controlled $\mathrm{RH}$ to mirror or the ambient RH probe to capture, thus frustrating the RH correction routines. However, modes in the EF and DF results can be determined to be non-hysteretic on other criteria than unity size ratio. The simplest criterion that indicates non-hysteretic modes without depending on direct comparison to ambient size is similar size ratio for the EF mode with the highest size ratio and DF mode with the smallest. Roughly $75 \%$ of measurements during the winter contained modes that met this criterion. This size ratio of the non-hysteretic fractions can then be defined as a new effective unity. Using a standard set of similar criteria, a version of the dataset was created that applied determined unity values from EF and DF measurements to their associated Drying process results as well.

Though this technique is not perfectly rigorous, it is expected to produce a reasonable first-order approximation of the actual ambient hydration characteristics. Moreover, it significantly improves the qualification of modes as hysteretic (the primary result of the AS-TDMA), basing the determination on the set of criteria rather than a less reliable unity basis. Also, the offset was only applied to the DF, EF and Drying results together and did not change their relative results. Finally, this technique is applicable to every scan as either the EF or DF process results must have a mode that does not change due to phase transitions.

The qualification of DF and EF process modes as hysteretic is slightly more complicated than applying a threshold deviation from the corrected unity growth. Using a simple threshold of characteristic size ratio in this determination would skew the results, admitting more measurements at high RH where more particulate water is generally involved. To remove this bias, the hygroscopic growth model is applied to the results to simulate their equivalents for a standard $\mathrm{RH}$ (here, $60 \%$ ). A threshold departure of \pm 0.03 (for DF and EF, respectively) from unity ambient-to-final size ratio was then used as the criteria for the determination. While such hygroscopic manipulations are fraught by unknown surface tension and activity characteristics, the benefits here outweighed introduced error.

\section{A5 Multiply charged particles}

At this stage, no attempt has been made to recover the effects of multiply charged particles in the AS-TDMA results. This is due primarily to unfortunately unavailable, necessary knowledge of the concurrent ambient size distribution; but, also to the non-triviality of developing the necessary procedures. Based on the limited ambient size data available, it is expected that multiply charged particles will very rarely contribute more than $8 \%$ to the resulting AS-TDMA size distributions, save for the $0.1 \mu \mathrm{m}$ ambient diameter measurements. At that size, the normal contribution is closer to $18 \%$. This is significant, but note that multiply charged particles only blur "size-resolution" and are evident only when sharp transitions with size exist in the response to the inter-DMA process (i.e. when the lost "size resolution" becomes salient). In conclusion, it is possible, in principle, to retrieve these errors with data procedures; these have not yet been developed for the AS-TDMA; and this lack does not greatly undermine the value and use of this data set. 


\section{A6 Calibration}

In this final element of methodology the calibration techniques for the AS-TDMA are described. Similar to other TDMA systems, the RH probe calibration is derived from the instrument response to a known aerosol. The calibration of the other critical TDMA components, the flow meters and high voltage sources, were based on direct measurements.

The RH calibration was inferred from AS-TDMA measurements conducted on atomizer generated ammonium sulfate aerosol. The atomizer generated aerosol stream was conditioned to contain both meta-stable hydrated and crystalline particles by dividing the initially hydrated stream into two parts, drying one part with a Nafion bundle and recombining. In addition, the apportionment between the two streams was adjustable, allowing the manipulation of the final $\mathrm{RH}$ level for multiple calibration points. Before it entered the first classifier, it was allowed to come to equilibrium with ambient temperature. From the results of the AS-TDMA measurements made on this aerosol, the actual ambient and controlled RH were determined. The two could be calibrated independently with this aerosol as only the hydrated fraction (either ambient or post-DF process) is sensitive to RH. Thus, the magnitude of growth by the initially crystalline fraction in the DF process only reflects the RH in the second classifier and controlled RH probe. Conversely, the loss in particulate water in the EF and Drying by the initially hydrated fraction indicates the RH levels in the ambient classifier and ambient RH probe only. The actual RH levels required to sustain the water content detected were calculated using activity and surface tension data from Tang (Tang and Munkelwitz, 1994; Tang, 1996; Tang et al., 1997). For calculating the dry particle volume, the crystalline particles were assumed to be non-spherical with mobility equivalent diameters 1.02 times greater than their volume equivalent diameters (Biskos et al., 2006). Table A1 lists the values inferred from each process for each of the aerosol fractions. The quantity $\Delta \mathrm{Q}_{\text {sheath }} / \mathrm{HV}$ refers to variation in size selection accuracy between the two classifiers: $Q_{\text {sheath }}$ refers to the sheath flow rates and HV refers to the classifier high voltage levels. These are the two variables that determine classifier accuracy and are calibrated directly. The duplicity evident in Table A1 allows additional checks on the consistency of these variables during RH calibration.

Acknowledgements. We would like to thank the Electric Power Research Institute for supporting this research. Also, we gratefully acknowledge the cooperation and support of Jim Renfro and the park staff at Great Smoky Mountains National Park during these measurement campaigns.

Edited by: B. Ervens

\section{References}

Berg, O. H., Swietlicki, E., and Krejci, R.: Hygroscopic growth of aerosol particles in the marine boundary layer over the $\mathrm{Pa}$ cific and Southern Oceans during the First Aerosol Characterization Experiment (ACE 1), J. Geophys. Res., 103, 16535-16545, doi:10.1029/97jd02851, 1998.

Biskos, G., Paulsen, D., Russell, L. M., Buseck, P. R., and Martin, S. T.: Prompt deliquescence and efflorescence of aerosol nanoparticles, Atmos. Chem. Phys., 6, 4633-4642, doi:10.5194/acp-64633-2006, 2006.

Brink, H. M. T., Veefkind, J. P., Waijers-Ijpelaan, A., and van der Hage, J. C.: Aerosol light-scattering in The Netherlands, Atmos. Environ., 30, 4251-4261, 1996.

Brooks, S. D., Wise, M. E., Cushing, M., and Tolbert, M. A.: Deliquescence behavior of organic/ammonium sulfate aerosol, Geophys. Res. Lett., 29, 1917, doi:10.1029/2002g1014733, 2002.

Carrico, C. M., Rood, M. J., Ogren, J. A., Neusüß, C., Wiedensohler, A., and Heintzenberg, J.: Aerosol Optical properties at Sagres, Portugal during ACE-2, Tellus B, 52, 694-715, doi:10.1034/j.1600-0889.2000.00049.x, 2000.

Carrico, C. M., Kus, P., Rood, M. J., Quinn, P. K., and Bates, T. S.: Mixtures of pollution, dust, sea salt, and volcanic aerosol during ACE-Asia: Radiative properties as a function of relative humidity, J. Geophys. Res., 108, 8650, doi:10.1029/2003jd003405, 2003.

Charlson, R. J., Vanderpol, A. H., Covert, D. S., Waggoner, A. P. and Ahlquist, N. C.: $\mathrm{H}_{2} \mathrm{SO}_{4} /\left(\mathrm{NH}_{4}\right)_{2} \mathrm{SO}_{4}$ background aerosol: Optical detection in St. Louis region, Atmos. Environ., 8, 1257 1267, 1974.

Choi, M. Y. and Chan, C. K.: The Effects of Organic Species on the Hygroscopic Behaviors of Inorganic Aerosols, Environ. Sci. Technol., 36, 2422-2428, doi:10.1021/es0113293, 2002.

Ciobanu, V. G., Marcolli, C., Krieger, U. K., Zuend, A., and Peter, T.: Efflorescence of Ammonium Sulfate and Coated Ammonium Sulfate Particles: Evidence for Surface Nucleation, J. Phys. Chem. A, 114, 9486-9495, doi:10.1021/jp103541w, 2010.

Clegg, S. L., Brimblecombe, P., and Wexler, A. S.: Thermodynamic Model of the System $\mathrm{H}^{+}-\mathrm{NH}_{4}^{+}-\mathrm{Na}^{+}-\mathrm{SO}_{4}^{2-}-\mathrm{NO}_{3}^{-}$$\mathrm{Cl}^{-}-\mathrm{H}_{2} \mathrm{O}$ at $298.15 \mathrm{~K}$, J. Phys. Chem. A, 102, 2155-2171, doi:10.1021/jp973043j, 1998a.

Clegg, S. L., Brimblecombe, P., and Wexler, A. S.: Thermodynamic Model of the System $\mathrm{H}^{+}-\mathrm{NH}_{4}^{+}-\mathrm{SO}_{4}^{2-}-\mathrm{NO}_{3}^{-}-\mathrm{H}_{2} \mathrm{O}$ at Tropospheric Temperatures, J. Phys. Chem. A, 102, 2137-2154, doi:10.1021/jp973042r, 1998b.

Clegg, S. L. and Brimblecombe, P.: Comment on the "Thermodynamic Dissociation Constant of the Bisulfate Ion from Raman and Ion Interaction Modeling Studies of Aqueous Sulfuric Acid at Low Temperatures", J. Phys. Chem. A, 109, 2703-2706, doi:10.1021/jp0401170, 2005.

Colberg, C. A., Luo, B. P., Wernli, H., Koop, T., and Peter, Th.: A novel model to predict the physical state of atmospheric $\mathrm{H}_{2} \mathrm{SO}_{4} / \mathrm{NH}_{3} / \mathrm{H}_{2} \mathrm{O}$ aerosol particles, Atmos. Chem. Phys., 3, 909-924, doi:10.5194/acp-3-909-2003, 2003.

Cruz, C. N. and Pandis, S. N.: Deliquescence and Hygroscopic Growth of Mixed Inorganic-Organic Atmospheric Aerosol, Environ. Sci. Technol., 34, 4313-4319, doi:10.1021/es9907109, 2000.

Day, D. E. and Malm, W. C.: Aerosol light scattering measure- 
ments as a function of relative humidity: a comparison between measurements made at three different sites, Atmos. Environ., 35, 5169-5176, 2001.

Day, D. E., Malm, W. C., and Ames, R. B.: Final Report - Southeastern Aerosol and Visibility Study, 2001.

Dougle, P. G., Veefkind, J. P., and ten Brink, H. M.: Crystallisation of mixtures of ammonium nitrate, ammonium sulphate and soot, J. Aerosol Sci., 29, 375-386, 1998.

Engelhart, G. J., Hildebrandt, L., Kostenidou, E., Mihalopoulos, N., Donahue, N. M., and Pandis, S. N.: Water content of aged aerosol, Atmos. Chem. Phys., 11, 911-920, doi:10.5194/acp-11911-2011, 2011.

Fierz-Schmidhauser, R., Zieger, P., Gysel, M., Kammermann, L., DeCarlo, P. F., Baltensperger, U., and Weingartner, E.: Measured and predicted aerosol light scattering enhancement factors at the high alpine site Jungfraujoch, Atmos. Chem. Phys., 10, 23192333, doi:10.5194/acp-10-2319-2010, 2010.

Gasparini, R., Li, R., and Collins, D. R.: Integration of size distributions and size-resolved hygroscopicity measured during the Houston Supersite for compositional categorization of the aerosol, Atmos. Environ., 38, 3285-3303, 2004.

Gasparini, R., Collins, D. R., Andrews, E., Sheridan, P. J., Ogren, J. A., and Hudson, J. G.: Coupling aerosol size distributions and size-resolved hygroscopicity to predict humidity-dependent optical properties and cloud condensation nuclei spectra, J. Geophys. Res., 111, D05S13, doi:10.1029/2005jd006092, 2006.

Grant, K. E., Chuang, C. C., Grossman, A. S., and Penner, J. E.: Modeling the spectral optical properties of ammonium sulfate and biomass burning aerosols: parameterization of relative humidity effects and model results, Atmos. Environ., 33, 26032620, 1999.

Gysel, M., McFiggans, G. B., and Coe, H.: Inversion of tandem differential mobility analyser (TDMA) measurements, J. Aerosol Sci., 40, 134-151, 2009.

Hansson, H. C., Rood, M. J., Koloutsou-Vakakis, S., Hämeri, K., Orsini, D., and Wiedensohler, A.: $\mathrm{NaCl}$ Aerosol Particle Hygroscopicity Dependence on Mixing with Organic Compounds, J. Atmos. Chem., 31, 321-346, doi:10.1023/a:1006174514022, 1998.

Haywood, J. M., Roberts, D. L., Slingo, A., Edwards, J. M., and Shine, K. P.: General Circulation Model Calculations of the Direct Radiative Forcing by Anthropogenic Sulfate and Fossil-Fuel Soot Aerosol, J. Climate, 10, 1562-1577, doi:10.1175/15200442(1997)010<1562:GCMCOT>2.0.CO;2, 1997.

Khlystov, A., Stanier, C. O., Takahama, S., and Pandis, S. N.: Water content of ambient aerosol during the Pittsburgh Air Quality Study, J. Geophys. Res., 110, D07S10, doi:10.1029/2004jd004651, 2005.

Lowenthal, D., Zielinska, B., Mason, B., Samy, S., Samburova, V., Collins, D., Spencer, C., Taylor, N., Allen, J., and Kumar, N.: Aerosol characterization studies at Great Smoky Mountains National Park, summer 2006, J. Geophys. Res., 114, D08206, doi:10.1029/2008jd011274, 2009.

Marcolli, C., Luo, B., and Peter, T.: Mixing of the Organic Aerosol Fractions: Liquids as the Thermodynamically Stable Phases, J. Phys. Chem. A, 108, 2216-2224, doi:10.1021/jp0360801, 2004.

Martin, S. T.: Phase Transitions of Aqueous Atmospheric Particles, Chem. Rev., 100, 3403-3454, doi:10.1021/cr990034t, 2000.

Martin, S. T., Han, J., H., Hung, H. M.: The size effect of hematite and corundum inclusions on the efflorescence relative humidities of aqueous ammonium sulfate particles, Geophys. Res. Lett., 28, 2601-2604, doi:10.1029/2001g1013120, 2001.

Martin, S. T., Hung, H.-M., Park, R. J., Jacob, D. J., Spurr, R. J. D., Chance, K. V., and Chin, M.: Effects of the physical state of tropospheric ammonium-sulfate-nitrate particles on global aerosol direct radiative forcing, Atmos. Chem. Phys., 4, 183-214, doi:10.5194/acp-4-183-2004, 2004.

Martin, S. T., Rosenoern, T., Chen, Q., and Collins, D. R.: Phase changes of ambient particles in the Southern Great Plains of Oklahoma, Geophys. Res. Lett., 35, L22801, doi:10.1029/2008g1035650, 2008.

Mifflin, A. L., Smith, M. L., and Martin, S. T.: Morphology hypothesized to influence aerosol particle deliquescence, Phys. Chem. Chem. Phys., 11, 10095-10107, 2009.

Pitchford, M., Malm, W., Schictel, B., Kumar, N., Lowenthal, D., and Hand, J.: Revised Algorithm for Estimating Light Extinction from IMPROVE Particle Speciation Data, J. Air Waste Manage., 57, 1326-1336, doi:10.3155/1047-3289.57.11.1326, 2007.

Pitchford, M. L. and McMurry, P. H.: Relationship Between Measured Water-Vapor Growth and Chemistry of Atmospheric Aerosol for Grand-Canyon, Arizona, in Winter 1990, Atmos. Environ., 28, 827-839, 1994.

Rissler, J., Vestin, A., Swietlicki, E., Fisch, G., Zhou, J., Artaxo, P., and Andreae, M. O.: Size distribution and hygroscopic properties of aerosol particles from dry-season biomass burning in Amazonia, Atmos. Chem. Phys., 6, 471-491, doi:10.5194/acp6-471-2006, 2006.

Rood, M. J., Covert, D. S., and Larson, T. V.: Hygroscopic properties of atmospheric aerosol in Riverside, California, Tellus B, 39B, 383-397, doi:10.1111/j.1600-0889.1987.tb00201.x, 1987.

Rood, M. J., Shaw, M. A., Larson, T. V., and Covert, D. S.: Ubiquitous nature of ambient metastable aerosol, Nature, 337, 537-539, 1989.

Rosenoern, T., Schlenker, J. C., and Martin, S. T.: Hygroscopic Growth of Multicomponent Aerosol Particles Influenced by Several Cycles of Relative Humidity, J. Phys. Chem. A, 112, 23782385, doi:10.1021/jp0771825, 2008.

Rosenoern, T., Paulsen, D., and Martin, S. T.: The 1-by-3 Tandem Differential Mobility Analyzer for Measurement of the Irreversibility of the Hygroscopic Growth Factor, Aerosol Sci. Tech., 43, 641-652, 2009.

Santarpia, J. L., Li, R., and Collins, D. R.: Direct measurement of the hydration state of ambient aerosol populations, J. Geophys. Res., 109, D18209, doi:10.1029/2004jd004653, 2004.

Seinfeld, J. H. and Pandis, S. N.: Atmospheric Chemistry and Physics, from Air Pollution To Climate Change, 2nd edition, John Wiley \& Sons, Inc., Hoboken, New Jersey, 478-483, 2006.

Shaw, M. A. and Rood, M. J.: Measurement of the crystallization humidities of ambient aerosol particles, Atmos. Environ. A-Gen., 24, 1837-1841, 1990.

Sjogren, S., Gysel, M., Weingartner, E., Alfarra, M. R., Duplissy, J., Cozic, J., Crosier, J., Coe, H., and Baltensperger, U.: Hygroscopicity of the submicrometer aerosol at the high-alpine site Jungfraujoch, $3580 \mathrm{~m}$ a.s.1., Switzerland, Atmos. Chem. Phys., 8, 5715-5729, doi:10.5194/acp-8-5715-2008, 2008.

Smith, M. L., Kuwata, M., and Martin, S. T.: Secondary Organic Material Produced by the Dark Ozonolysis of $\alpha$-Pinene Minimally Affects the Deliquescence and Efflorescence of Ammo- 
nium Sulfate, Aerosol Sci. Tech., 45, 244-261, 2011.

Stanier, C. O., Khlystov, A. Y., Chan, W. R., Mandiro, M., and Pandis, S. N.: A Method for the In Situ Measurement of Fine Aerosol Water Content of Ambient Aerosols: The Dry-Ambient Aerosol Size Spectrometer (DAASS) Special Issue of Aerosol Science and Technology on Findings from the Fine Particulate Matter Supersites Program, Aerosol Sci. Tech., 38, 215-228, doi:10.1080/02786820390229525, 2004.

Swietlicki, E., Zhou, J., Covert, D. S., Hämeri, K., Busch, B., Väkeva, M., Dusek, U., Berg, O. H., Wiedensohler, A., Aalto, P., Mäkelä, J., Martinsson, B. G., Papaspiropoulos, G., Mentes, B., Frank, G., and Stratmann, F.: Hygroscopic properties of aerosol particles in the north-eastern Atlantic during ACE-2, Tellus B, 52, 201-227, doi:10.1034/j.1600-0889.2000.00036.x, 2000.

Swietlicki, E., Hansson, H. C., Hämeri, K., Svenningsson, B., Massling, A., McFiggans, G., McMurry, P. H., Petäjä, T., Tunved, P., Gysel, M., Topping, D., Weingartner, E., Baltensperger, U., Rissler, J., Wiedensohler, A., and Kulmala, M.: Hygroscopic properties of submicrometer atmospheric aerosol particles measured with H-TDMA instruments in various environments - a review, Tellus B, 60, 432-469, doi:10.1111/j.16000889.2008.00350.x, 2008.

Tang, I. N., Munkelwitz, H. R., and Davis, J. G.: Aerosol growth studies - IV. Phase transformation of mixed salt aerosols in a moist atmosphere, J. Aerosol Sci., 9, 505-511, 1978.

Tang, I. N. and Munkelwitz, H. R.: An investigation of solute nucleation in levitated solution droplets, J. Colloid. Interf. Sci., 98, 430-438, 1984.
Tang, I. N. and Munkelwitz, H. R.: Water activities, densities, and refractive indices of aqueous sulfates and sodium nitrate droplets of atmospheric importance, J. Geophys. Res., 99, 18801-18808, doi:10.1029/94jd01345, 1994.

Tang, I. N.: Chemical and size effects of hygroscopic aerosols on light scattering coefficients, J. Geophys. Res., 101, 1924519250, doi:10.1029/96jd03003, 1996.

Tang, I. N., Tridico, A. C., and Fung, K. H.: Thermodynamic and optical properties of sea salt aerosols, J. Geophys. Res., 102, 23269-23275, doi:10.1029/97jd01806, 1997.

Wang, J., Hoffmann, A. A., Park, R. J., Jacob, D. J., and Martin, S. T.: Global distribution of solid and aqueous sulfate aerosols: Effect of the hysteresis of particle phase transitions, J. Geophys. Res., 113, D11206, doi:10.1029/2007jd009367, 2008a.

Wang, J., Jacob, D. J., and Martin, S. T.: Sensitivity of sulfate direct climate forcing to the hysteresis of particle phase transitions, J. Geophys. Res., 113, D11207, doi:10.1029/2007jd009368, 2008b.

Wang, W., Rood, M. J., Carrico, C. M., Covert, D. S., Quinn, P. K., and Bates, T. S.: Aerosol optical properties along the northeast coast of North America during the New England Air Quality Study-Intercontinental Transport and Chemical Transformation 2004 campaign and the influence of aerosol composition, J. Geophys. Res., 112, D10S23, doi:10.1029/2006jd007579, 2007.

Zhou, J. C., Swietlicki, E., Berg, O. H., Aalto, P. P., Hameri, K., Nilsson, E. D., and Leck, C.: Hygroscopic properties of aerosol particles over the central Arctic Ocean during summer, J. Geophys. Res.-Atmos., 106, 32111-32123, 2001. 